\title{
Large-Eddy Simulations of a Drizzling, Stratocumulus-Topped Marine Boundary Layer
}

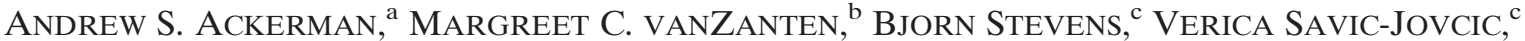

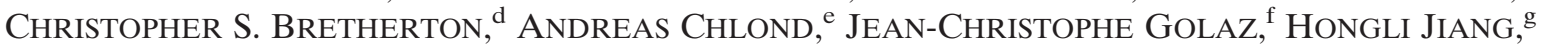 \\ Marat Khairoutdinov, ${ }^{\text {h }}$ Steven K. Krueger, ${ }^{i}$ David C. Lewellen, ${ }^{j}$ Adrian Lock, ${ }^{k}$ \\ Chin-Hoh Moeng, ${ }^{1}$ Kozo Nakamura, ${ }^{\mathrm{m}}$ Markus D. Petters, ${ }^{\mathrm{n}}$ JefFerson R. Snider, ${ }^{\circ}$ \\ SONJA WEINBRECHT, ${ }^{\mathrm{p}}$ AND MiKe ZULAUF ${ }^{\mathrm{i}}$ \\ ${ }^{a}$ NASA Goddard Institute for Space Studies, New York, New York \\ ${ }^{b}$ Royal Netherlands Meteorological Institute, De Bilt, Netherlands \\ ${ }^{c}$ Department of Atmospheric and Oceanic Sciences, University of California, Los Angeles, Los Angeles, California \\ ${ }^{d}$ Department of Atmospheric Sciences, University of Washington, Seattle, Washington \\ ${ }^{e}$ Max Planck Institute for Meteorology, Hamburg, Germany \\ ${ }^{f}$ UCAR Visiting Scientist Program, NOAA/Geophysical Fluid Dynamics Laboratory, Princeton, New Jersey \\ ${ }^{g}$ NOAA/Earth System Research Laboratory, Boulder, Colorado \\ ${ }^{h}$ School of Marine and Atmospheric Sciences, Stony Brook University, Stony Brook, New York \\ ${ }^{i}$ Department of Meteorology, University of Utah, Salt Lake City, Utah \\ ${ }^{j}$ MAE Department, West Virginia University, Morgantown, West Virginia \\ ${ }^{k}$ Met Office, Exeter, United Kingdom \\ ${ }^{l}$ National Center for Atmospheric Research, Boulder, Colorado \\ ${ }^{m}$ Frontier Research Center for Global Change, Japan Agency for Marine-Earth Science and Technology, Yokahama, Japan \\ ${ }^{n}$ Department of Atmospheric Science, Colorado State University, Fort Collins, Colorado \\ ${ }^{\circ}$ Department of Atmospheric Science, University of Wyoming, Laramie, Wyoming \\ ${ }^{p}$ Department of Meteorology, University of Reading, Reading, United Kingdom
}

(Manuscript received 4 March 2008, in final form 13 August 2008)

\begin{abstract}
Cloud water sedimentation and drizzle in a stratocumulus-topped boundary layer are the focus of an intercomparison of large-eddy simulations. The context is an idealized case study of nocturnal stratocumulus under a dry inversion, with embedded pockets of heavily drizzling open cellular convection. Results from 11 groups are used. Two models resolve the size distributions of cloud particles, and the others parameterize cloud water sedimentation and drizzle. For the ensemble of simulations with drizzle and cloud water sedimentation, the mean liquid water path (LWP) is remarkably steady and consistent with the measurements, the mean entrainment rate is at the low end of the measured range, and the ensemble-average maximum vertical wind variance is roughly half that measured. On average, precipitation at the surface and at cloud base is smaller, and the rate of precipitation evaporation greater, than measured. Including drizzle in the simulations reduces convective intensity, increases boundary layer stratification, and decreases LWP for nearly all models. Including cloud water sedimentation substantially decreases entrainment, decreases convective intensity, and increases LWP for most models. In nearly all cases, LWP responds more strongly to cloud water sedimentation than to drizzle. The omission of cloud water sedimentation in simulations is strongly discouraged, regardless of whether or not precipitation is present below cloud base.
\end{abstract}

\section{Introduction}

Marine boundary layer clouds cover vast areas of the global ocean and exert a substantial shortwave radiative

Corresponding author address: Andrew S. Ackerman, NASA Goddard Institute for Space Studies, New York, NY 10025.

E-mail: andrew.ackerman@nasa.gov forcing on the global heat budget (Klein and Hartmann 1993). Evidence suggests they constitute a leading-order uncertainty in cloud feedbacks in global climate models (Bony and Dufresne 2005), largely attributable to difficulties in representing them in large-scale models. The Global Energy and Water Exchange Cloud System Study (GCSS) project was developed to improve cloud parameterizations in climate and numerical weather 
prediction models (Randall et al. 2003). The GCSS Boundary Layer Cloud Working Group (BLCWG) has conducted a number of workshops devoted to idealized case studies of low-lying clouds simulated with a range of models. The preceding BLCWG intercomparison of large-eddy simulations (LES) concerned the first research flight of the second Dynamics and Chemistry of Marine Stratocumulus Field Study (DYCOMS-II), in which very dry air overlay a stratocumulus-topped marine boundary layer, with average cloud droplet concentrations of $\sim 140 \mathrm{~cm}^{-3}$ (vanZanten et al. 2005) and no measurable precipitation below cloud base (Stevens et al. 2005b). Models that reduced subgrid-scale mixing at cloud top were found best able to maintain sufficient radiative cooling while concurrently limiting entrainment at cloud top, resulting in a well-mixed boundary layer topped by an optically thick cloud layer, as observed. Cloud water sedimentation and drizzle were ignored in the simulations, which is a traditional approach in studies of nonprecipitating clouds.

A number of investigations over the years have considered the effects of drizzle on the stratocumulustopped boundary layer, and here we scratch the surface of that literature. Brost et al. (1982) and Nicholls (1984) made in situ measurements and found drizzle fluxes comparable to turbulent moisture fluxes. Brost et al. (1982) suggested that the combination of latent heating in the cloud and cooling below can stabilize the boundary layer and thereby decouple the cloud from the subcloud layer. Nicholls (1984) confirmed this idea with a simple model and furthermore found that drizzle reduces entrainment of overlying air by the boundary layer. From analysis of other in situ measurements, Paluch and Lenschow (1991) proposed a conceptual model in which stabilization of the subcloud layer results from evaporation of heavy drizzle throughout the subcloud layer, which leads to heat and moisture accumulating in the surface layer. The resulting convective instability is relieved by cumuliform convection that breaks up a stratiform cloud layer. They differentiated this heavily drizzling regime from one in which light drizzle completely evaporates before reaching the surface, thereby maintaining the instability throughout the depth of the subcloud layer. Jiang et al. (2002) used eddy-resolving simulations with bin microphysics to show just the opposite: when light drizzle completely evaporates before reaching the surface, the subcloud layer becomes destabilized with respect to the surface, and cumuliform convection develops to couple the subcloud and cloud layers. In contrast, when heavy drizzle reaches the surface, no cumuliform convection developed in their simulations.
Stevens et al. (1998) used LES with bin microphysics to show that heavy drizzle ( $\sim 1 \mathrm{~mm} \mathrm{day}^{-1}$ at the surface) not only stabilizes the cloud layer with respect to the subcloud layer, but also dries out the downdrafts such that they become buoyant above mean cloud base, thereby diminishing the generation of turbulence kinetic energy. The delayed downdraft buoyancy induced by the sedimentation flux divergence at cloud top, not realized until all the condensed water evaporates above mean cloud base, is described as "potential buoyancy" by Stevens et al. (1998). In that study, liquid water path (LWP) was found to be dramatically reduced by heavy drizzle, owing to the surface moisture sink of precipitation and reduced mixing between the cloud and subcloud layers. ${ }^{1}$ Stevens et al. (1998) also found entrainment to decrease in the presence of heavy drizzle. However, with little difference between the humidity above and within the boundary layer, there was little effect of the reduced entrainment on boundary layer moisture in their simulations. Furthermore, Stevens et al. (1998) proposed a testable hypothesis that shallow, well-mixed, radiatively driven, stratocumulus-topped boundary layers with deep, penetrative downdrafts cannot persist in the presence of heavy drizzle.

Related to concerns regarding boundary layer dynamics, there is considerable climate-related interest in so-called indirect aerosol effects (radiative forcings induced by changes in aerosol concentrations through modification of cloud properties). As recognized by Twomey (1974), increased aerosol concentrations can enhance cloud droplet concentrations, and distributing a fixed amount of water over more-and thus smallerdroplets results in more reflective clouds, which results in a negative radiative forcing. But smaller droplets also produce drizzle less efficiently, and a number of studies have shown that decreased drizzle can lead to thicker clouds with more condensed water (e.g., Albrecht 1989; Pincus and Baker 1994), thereby reflecting even more sunlight.

Despite expectations of decreased drizzle leading to increased cloud water, measurements of ship tracksaerosol plumes within marine stratocumulus cloud decks-indicate that cloud water tends to decrease, if anything, rather than increase in clouds with higher droplet concentrations (Ackerman et al. 2000; Platnick et al. 2000; Coakley and Walsh 2002). A possible explanation is provided by a modeling study (Ackerman

\footnotetext{
${ }^{1}$ Although the boundary layer is not well mixed in such a scenario, the cumuliform convection that develops does couple the cloud and subcloud layers, leading Stevens et al. (1998) to comment that "decoupling" is a carelessly used term in the literature, which we perpetuate here.
} 
et al. 2004) that showed LWP increasing with droplet concentrations only when sufficient drizzle reaches the surface (more than $\sim 0.1 \mathrm{~mm} \mathrm{day}^{-1}$ ), a condition favored by moist air overlying the boundary layer. Otherwise, reductions in drizzle (or even in just cloud water sedimentation) induced by increasing droplet concentrations were found instead to reduce LWP by increasing entrainment of dry air from aloft. The potential buoyancy mechanism of Stevens et al. (1998) was suggested as the mechanism underlying the increase in entrainment with increasing droplet concentrations. However, Bretherton et al. (2007), who also found that decreasing cloud water sedimentation can reduce LWP, argued that the potential buoyancy concept does not apply to cloud water sedimentation, and that diminished entrainment results instead from a sedimentationinduced reduction in the evaporative cooling available to promote mixing at cloud top.

Notwithstanding the likelihood that drizzle can strongly affect boundary layer dynamics, it may not be the predominant cause of decoupling in cloud-topped boundary layers, as there is a substantial body of theoretical work showing that such decoupling can arise from the dynamics of deepening boundary layers independent of drizzle (e.g., Krueger et al. 1995a; Bretherton and Wyant 1997; Stevens 2000; Lewellen and Lewellen 2002). Nonetheless, here we focus on the effects of drizzle and cloud water sedimentation on the dynamics and bulk properties of a stratocumulus-topped marine boundary layer, through simulations based on an idealization of a cloud deck with patchy drizzle. Another aim is to evaluate how well an assortment of LES models are able to match observed cloud properties, precipitation, and dynamics. We note that the BLCWG has also compared single-column models using the same specifications developed for this study, as described by Wyant et al. (2007). Section 2 below describes the specifications used here, section 3 presents the results, section 4 discusses the results and the prospects of using such intercomparisons to isolate the performance of microphysical schemes, and section 5 summarizes our findings.

\section{Setup of simulations}

The specifications for the simulation intercomparison are based on an idealization of nocturnal aircraft measurements obtained during the second research flight (RF02) of DYCOMS-II (Stevens et al. 2003a). The cloud field sampled on that flight was bimodal, with pockets of heavily drizzling open cells amid a deck of closed-cell stratocumulus that was drizzling lightly (vanZanten and Stevens 2005; Stevens et al. 2005a).
These two populations not only had different rates of precipitation, but their aerosol distributions were also notably different (Petters et al. 2006). For the intercomparison, the initial thermodynamic conditions represent an average over these two cloud populations, while the prescribed microphysical conditions represent an average over the open cells. The latter is an ad hoc modification made after the workshop (at the 2005 panGCSS meeting in Athens, Greece) to compensate for the greatest domain-average surface precipitation in the preliminary simulation ensemble being about half that observed. In stratocumulus, the precipitation rate at cloud base is not expected to be a linear function of the liquid water path (e.g., Pawlowska and Brenguier 2003; Comstock et al. 2004; vanZanten et al. 2005), so even if the models and measurements were perfect, the average thermodynamic and microphysical conditions would not be expected to produce a simulated cloud field that matches the measurement average. Because of this fundamental problem, here we consider the trends among the model simulations as much if not more so than the comparisons between simulations and measurements.

\section{a. Initial conditions}

The initial atmospheric profiles of wind, moisture, and temperature were composited from the horizontally averaged measurements as

$$
\begin{aligned}
& u=3+4.3 z / 1000 \mathrm{~m} \mathrm{~s}^{-1} \\
& v=-9+5.6 z / 1000 \mathrm{~m} \mathrm{~s}^{-1}, \\
& q_{t}=\left\{\begin{array}{l}
9.45 \mathrm{~g} \mathrm{~kg}^{-1} z<z_{i} \\
5-3\left[1-\exp \left(\left[z-z_{i}\right] / 500\right)\right] \mathrm{g} \mathrm{kg}^{-1}
\end{array}\right. \\
& \theta_{l}=\left\{\begin{array}{l}
288.3 \mathrm{~K} \\
295+\left(z-z_{i}\right)^{1 / 3} \mathrm{~K} \quad \text { otherwise }
\end{array}\right.
\end{aligned}
$$$$
q_{t}=\left\{\begin{array}{l}
9.45 \mathrm{~g} \mathrm{~kg}^{-1} \quad z<z_{i} \\
5-3\left[1-\exp \left(\left[z-z_{i}\right] / 500\right)\right] \mathrm{g} \mathrm{kg}^{-1} \quad \text { otherwise }
\end{array},\right.
$$

where $u$ and $v$ are westerly and southerly winds, $z$ is altitude in $\mathrm{m}, z_{i}$ the initial inversion height of $795 \mathrm{~m}, q_{t}$ the total water mixing ratio (sum of the mass mixing ratios of water vapor, $q_{v}$, and liquid water, $q_{l}$ ), and $\theta_{l}$ a linearized liquid-water potential temperature:

$$
\theta_{l}=\left(p_{\text {ref }} / p\right)^{R_{d} / c_{p}}\left(T-L q_{l} / c_{p}\right),
$$

in which $p$ and $T$ are atmospheric pressure and temperature, $p_{\text {ref }}=1000 \mathrm{mb}, R_{d}=287 \mathrm{~J} \mathrm{~kg}^{-1} \mathrm{~K}^{-1}, c_{p}=1004$ $\mathrm{J} \mathrm{kg}^{-1} \mathrm{~K}^{-1}$, and $L=2.5 \mathrm{MJ} \mathrm{kg}^{-1}$. Surface pressure is assumed to be constant at $1017.8 \mathrm{hPa}$. To accelerate the spinup of convection, it was recommended to pseudorandomly perturb the initial temperatures within the boundary layer about their horizontal means with an 
amplitude of $0.1 \mathrm{~K}$, and to initialize the turbulence kinetic energy (TKE) in models with prognostic subgridscale schemes at $1 \mathrm{~m}^{2} \mathrm{~s}^{-2}$.

For comparison with the previous BLCWG case, the first research flight (RF01) of DYCOMS-II, we note that the air above the inversion is moister and cooler here, and both differences are conducive to drizzle. For a 50-m thick inversion layer the initial jumps in $q_{t}$ and $\theta_{l}$ in the present case are $-4.7 \mathrm{~g} \mathrm{~kg}^{-1}$ and $10.4 \mathrm{~K}$, compared to $-7.5 \mathrm{~g} \mathrm{~kg}^{-1}$ and $12.2 \mathrm{~K}$ in Stevens et al. (2005b). Thus, while the previous case was unstable with respect to the classic cloud-top entrainment instability threshold (Deardorff 1980a; Randall 1980), the present case is not. With such dry, warm inversions, neither case is close to the "cloud deepening through entrainment" regime of Randall (1984) in which entrainment can lead to a thicker cloud layer; thus, entrainment is expected to thin the cloud layer in both cases.

\section{b. Forcings}

As in previous BLCWG stratocumulus cases, no large-scale horizontal flux divergences of $\theta_{l}$ or $q_{t}$ are considered; thus the conceptual framework is of a model grid advecting with the mean wind, in which there is no change in the imposed boundary conditions over the duration of the simulation. Other than surface boundary conditions, all of the forcings are identical to those in Stevens et al. (2005b). Uniform divergence of the largescale horizontal winds: $D=3.75 \times 10^{-6} \mathrm{~s}^{-1}$ is assumed, chosen so that subsidence warming above the inversion balances the derived radiative cooling there. The largescale vertical wind is computed as $w_{\mathrm{LS}}=-D z$ and appears as a source term for each prognostic variable $\phi$ as $-w_{\mathrm{LS}} \partial \phi / \partial z$. A large-scale horizontal pressure gradient is included in the $u$ and $v$ equations by assuming that the geostrophic wind is given by the initial wind profile at a latitude of $31.5^{\circ} \mathrm{N}$. Radiative heating rates are computed every time step from the divergence of a longwave radiative flux profile in each model column using the parameterization from Stevens et al. (2005b):

$$
\begin{aligned}
F(z)= & F_{0} \exp [-Q(z, \infty)]+F_{1} \exp [-Q(0, z)] \\
& +a \rho_{i} c_{p} D H\left(z-z_{i}\right)\left[0.25\left(z-z_{i}\right)^{4 / 3}+z_{i}\left(z-z_{i}\right)^{1 / 3}\right],
\end{aligned}
$$

where

$$
Q\left(z_{1}, z_{2}\right)=\int_{z_{1}}^{z_{2}} \kappa \rho q_{l} d z
$$

in which $a=1 \mathrm{~K} \mathrm{~m}^{-1 / 3}, \rho$ is air density, $\rho_{\mathrm{i}}=1.12 \mathrm{~kg} \mathrm{~m}^{-3}$ (air density at initial $z_{i}$ ), $H$ is the Heaviside step func-
TABLE 1. Mean droplet concentration $\left(\mathrm{cm}^{-3}\right)$ averaged over cloudy segments of horizontal flight legs near cloud top and cloud base, where cloudy air is defined by cloud droplet concentration exceeding $20 \mathrm{~cm}^{-3}$ (values from vanZanten and Stevens 2005).

\begin{tabular}{lcc}
\hline \hline Flight leg & Open cells & Closed cells \\
\hline Cloud top & $56 \pm 16$ & $80 \pm 17$ \\
Cloud base & $54 \pm 14$ & $60 \pm 13$ \\
\hline
\end{tabular}

tion, $z_{i}$ is the lowermost altitude in a model column where $q_{t}=8 \mathrm{~g} \mathrm{~kg}^{-1}$, and $F_{0}=70 \mathrm{~W} \mathrm{~m}^{-2}, F_{1}=22 \mathrm{~W} \mathrm{~m}^{-2}$, and $\kappa=85 \mathrm{~m}^{2} \mathrm{~kg}^{-1}$. Theoretical justification for this parameterization is provided by Larson et al. (2007), where its range of applicability (which includes the conditions considered here) is discussed.

The only forcings that depart from Stevens et al. (2005b) are the surface boundary conditions, here taken from the measurements of vanZanten and Stevens (2005) and designed to minimize departures from the measurements while allowing the evolving wind field to feed back on the surface momentum fluxes. Upward sensible and latent heat fluxes, apart from any precipitation flux, are fixed at the measured averages of 16 and $93 \mathrm{~W} \mathrm{~m}^{-2}$, respectively, in which a surface air density of $1.21 \mathrm{~kg} \mathrm{~m}^{-3}$ is implicit. The upward surface momentum flux is computed as $-u_{i} u_{*}^{2} /|U|$, where wind components $u_{i}$ and magnitude $|U|$ are defined locally and the friction velocity is fixed at $u_{*}=0.25 \mathrm{~m} \mathrm{~s}^{-1}$. The latter was obtained from preliminary simulations using surfacesimilarity boundary conditions.

\section{c. Cloud microphysics}

For models that prescribe the number concentration of cloud droplets $\left(N_{d}\right)$, a uniform value of $N_{d}=55 \mathrm{~cm}^{-3}$ was specified, based on averages over horizontal flight legs within the open cells (see Table 1). For models with bin microphysics, an idealized, uniform aerosol distribution was derived from measurements, as described in appendix A. Models with bin microphysics are initialized without water droplets, implying an incipient cloud layer that is initially supersaturated. Activating large numbers of Aitken-mode particles during convection spinup would hamper precipitation development relative to models that fix $N_{d}$. To avoid such an undesirable course, the maximum supersaturation used for droplet activation is limited to $1 \%$ during the first hour, resulting in activation of $\sim 70 \mathrm{~cm}^{-3}$ droplets during that time. This limit is applied to droplet activation only, and not to condensational growth.

Bin microphysics models automatically treat sedimentation of cloud droplets, unlike other models that typically ignore the process. For those models cloud 
water sedimentation is included here by assuming a lognormal size distribution of droplets falling in a Stokes regime, in which the sedimentation flux is given by

$$
F=c\left[3 /\left(4 \pi \rho_{l} N_{d}\right)\right]^{2 / 3}\left(\rho q_{c}\right)^{5 / 3} \exp \left(5 \log ^{2} \sigma_{g}\right),
$$

where $c=1.19 \times 10^{8} \mathrm{~m}^{-1} \mathrm{~s}^{-1}$ (Rogers 1979), $\rho_{l}$ is the density of liquid water, $q_{c}$ the mass-mixing ratio of cloud water, and $\sigma_{g}$ the geometric standard deviation of the size distribution. A value of $\sigma_{g}=1.5$ was specified, based on the mean value minus one standard deviation of $\left(\overline{r^{2}}\right)^{3} /\left(\overline{r^{3}}\right)^{2}$ (where $r$ is droplet radius) reported by Martin et al. (1994) for stratocumulus in continental air masses. In retrospect, a value of $\sigma_{g}=1.2$ would have been more consistent with the cloud droplet size distributions measured during RF02, as well as being closer to the maritime average found by Martin et al. (1994). This smaller value, corresponding to a narrower size distribution, and nearly halving the sedimentation rate for a given cloud water and droplet number concentration, is considered in a sensitivity test.

\section{Results}

Beyond the results and analyses presented here, a complete set of the submitted model results is available at the GCSS Data Integration for Model Evaluation (DIME) Web site (http://gcss-dime.giss.nasa.gov). The models are described and the output variables defined in appendices B and C, respectively. Time series are interpolated to a uniform temporal grid with 300 -s spacing; profiles are interpolated to a uniform vertical grid with 2-m spacing.

\section{a. Simulations with drizzle and cloud water sedimentation}

\section{1) Domain AVERAGES}

After $2 \mathrm{~h}$ of simulation with drizzle and cloud water sedimentation included, the transient spinup of boundary layer convection has completed, and the simulation ensemble settles into a pseudo-steady state in which properties such as LWP, entrainment, precipitation, and the maximum of vertical wind variance $\overline{\left(w^{\prime 2}\right)}$ are nearly constant, as seen in Fig. 1. The middle half (middle two quartiles) of the ensemble characterizes the range of LWP estimated from the measurements remarkably well, and the full range of the ensemble is nearly twice again as broad. The entrainment rate in the simulations is computed here as $E=d z_{i} / d t+D z_{i}$ (where $z_{i}$ is the mean height of the $q_{t}=8 \mathrm{~g} \mathrm{~kg}^{-1}$ isosurface) and the ensemble is roughly centered on the low end of the measured range (derived from conservative tracers). The boundary layer is deepening in all the simulations, with a mean entrainment rate about twice the subsidence rate at the initial $z_{i}$, and thus none of the simulated boundary layers are in a true steady state. While agreement of the ensemble LWP and $E$ with measurements is favorable, further comparisons tend to be less so. For instance, the intensity of convection given by the maximum $\overline{w^{\prime 2}}$ is about half that measured. As shown below, the measurements suggest a well-mixed boundary layer, but a number of aspects of the simulations suggest some decoupling.

The ensemble range of domain-mean precipitation rates at the surface is substantial and the distribution is skewed, with the mean corresponding roughly to the lower end of the measured average and the median about half that (Fig. 1). At cloud base, the simulated precipitation varies widely among the simulations (Fig. 2 ). On the one hand, precipitation at cloud base and at the surface in more than half the simulations is substantially less than that measured. On the other hand, the results in a majority of simulations fall within $\pm 50 \%$ of the combined measurements of LWP and cloud-base precipitation. And while the fractional loss of precipitation below cloud base in most of the simulations exceeds that in the measurements, all the simulations fall within $\pm 50 \%$ of the combined measurements of LWP and fractional precipitation loss. Greater loss of precipitation below cloud base is observed when stratocumulus drizzle is less intense (vanZanten et al. 2005), consistent with the overall differences between the simulations and observations here. Correlations between LWP and precipitation are weak, though for both models that vary the efficiency of drizzle formation (DHARMA and UCLA), as the efficiency is increased, precipitation at the surface and at cloud base increases, while LWP and the fractional loss of precipitation both decrease. No clustering systematically related to microphysics schemes is evident, as results from the most complex methods (bin models of DHARMA and RAMS) and those from the simplest (single-moment schemes of NHM and Utah) are interspersed with those from the rest of the models, which use double-moment schemes. Such a lack of clustering suggests that in terms of simulated LWP and precipitation, intermodel differences in microphysics schemes are generally dominated by differences in model dynamics. Also seen in Fig. 2, the majority of simulations produce a fairly solid cloud deck, with cloud cover greater than $95 \%$ for all but two of the simulations. No integral measure of cloud cover is available for comparison with observations.

The impacts of cloud water sedimentation are substantial, as found elsewhere (Ackerman et al. 2004; Bretherton et al. 2007) and discussed in greater detail 

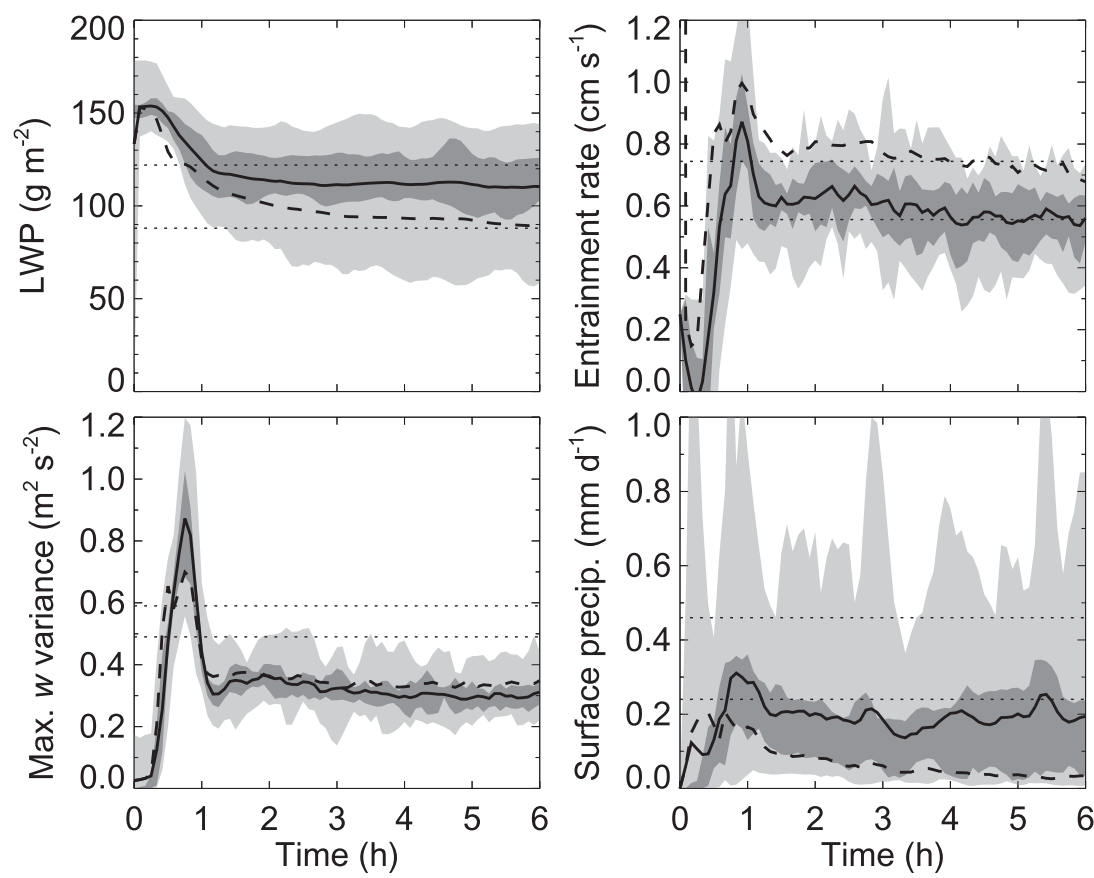

FIG. 1. Evolution of domain average LWP, entrainment rate (defined in text), maximum $\overline{w^{\prime 2}}$ (peak value in the $\overline{w^{\prime 2}}$ profile), and surface precipitation for simulations that include cloud water sedimentation and drizzle. Ensemble range, middle two quartiles, and mean denoted by light and dark shading and solid lines, respectively. Ensemble mean from simulations that include drizzle but not cloud water sedimentation denoted by dashed lines. Approximate ranges of measurements (averaged over closed and open cells) denoted by dotted lines, with upper and lower LWP values estimated from Stevens et al. (2003a) and aircraft soundings, respectively; entrainment rates from Faloona et al. (2005); maximum $\overline{w^{\prime 2}}$ from vanZanten and Stevens (2005); and precipitation from vanZanten et al. (2005).

later. Compared to the ensemble means with cloud water sedimentation omitted, including it reduces entrainment by $\sim 25 \%$ (Fig. 1). The diminished entrainment results in a cooler, moister boundary layer, with ensemble mean LWP increasing by $\sim 20 \%$, surface precipitation increasing roughly fourfold, and maximum $\overline{w^{\prime 2}}$ decreasing by $\sim 10 \%$.

\section{2) Profiles}

Excluding the scatter above the inversion layer, the ensemble distributions of $\theta_{l}$ and $q_{t}$ are tight (Fig. 3), with the observed $\theta_{l}$ profile well matched by the simulations while the gradient in the simulated $q_{t}$ profiles indicates a somewhat less well-mixed boundary layer than observed. Comparatively broader ensemble distributions are seen in all the other profiles, with the middle half of the distribution reproducing not only the observed $q_{l}$ but also the cloud fraction profile remarkably well.

The ensemble distribution of precipitation is even broader, and the middle half of the distribution falls between that measured in closed and open cells. The difference between closed and open cells is prominent in the precipitation measurements. The precipitation flux in the middle half of the ensemble is closer to that in the open cell measurements in the upper region of the cloud, and transitions to values closer to the closed cell measurements at lower elevations. The effect on precipitation of including cloud water sedimentation in the simulations is seen to be profound throughout the ensemble profile, and the differences increase with height. As might be expected in a lightly drizzling regime, the shape of the precipitation profile is dominated by cloud water sedimentation in that the total precipitation flux peaks near cloud top rather than near cloud base as found in heavily drizzling stratocumulus, both in measurements (e.g., Nicholls 1984) and in simulations (e.g., Ackerman et al. 2004). The domination of the precipitation flux by cloud water sedimentation in the upper half of the cloud layer is seen in Fig. 4 for the only simulation here where separation between sedimentation of cloud droplets and drizzle drops is readily available. As noted by vanZanten and Stevens (2005), it may not be possible to composite a representative profile from in situ 


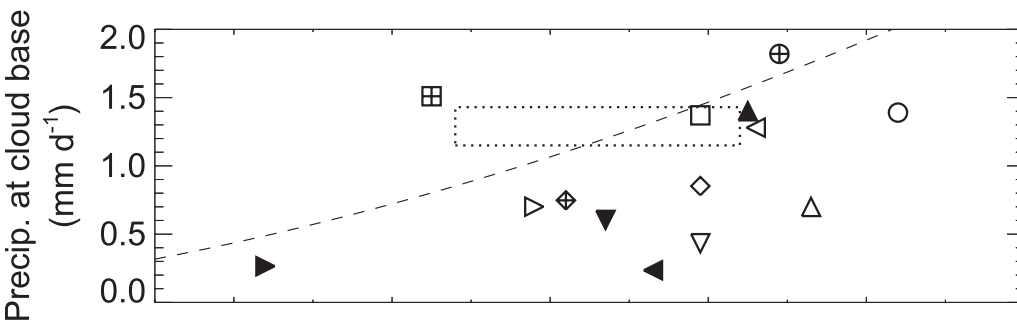

\section{$\diamond$ COAMPS \\ $\oplus$ COAMPS_SL \\ O DHARMA}

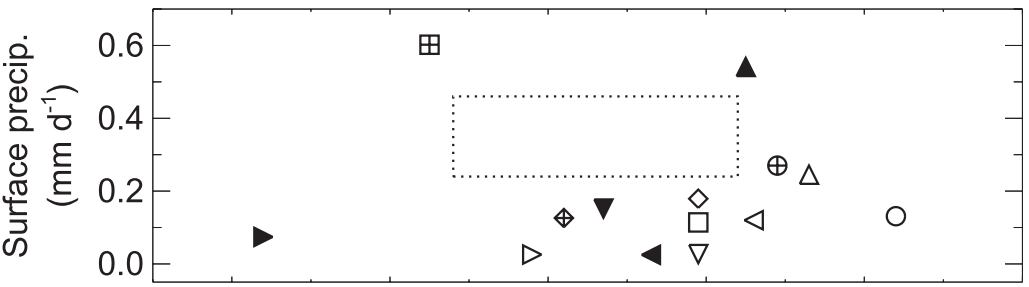

DHARMA_BO

MetO

MPI

$\triangle \mathrm{NHM}$

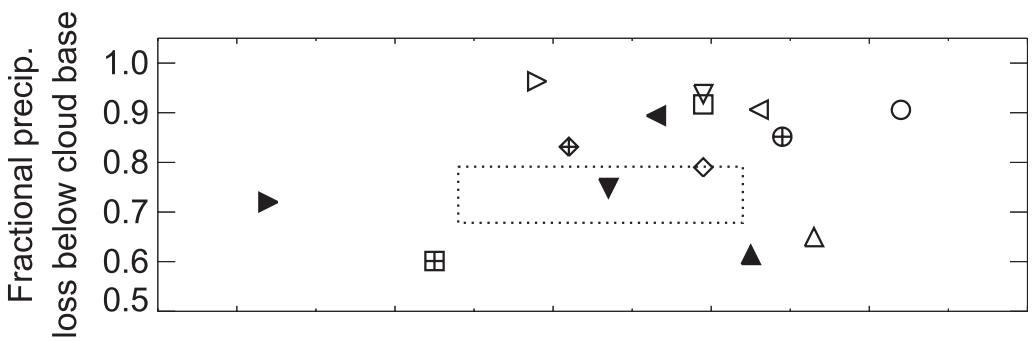

$\nabla$ RAMS

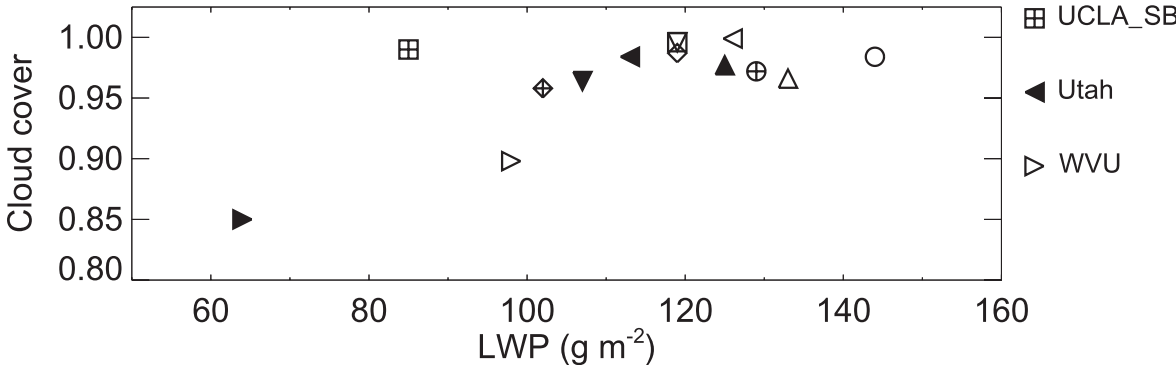

FIG. 2. Precipitation at cloud base, at the surface, their relative difference, and domain average cloud cover versus LWP, all averaged over last $4 \mathrm{~h}$ of simulations that include cloud water sedimentation and drizzle. Cloud base and cloud cover are defined in appendix C. Dotted boxes denote measurements (see Fig. 1). Precipitation includes all of the condensed water (cloud droplets and drizzle drops) for both the measurements and simulations. Symbol legend given at right. Dashed line is Comstock et al. (2004) fit to measurements of Peruvian stratocumulus, in which cloud-base precipitation was found to scale with $\left(\mathrm{LWP} / N_{d}\right)^{7 / 4}$, which we adapt by fixing $N_{d}=55 \mathrm{~cm}^{-3}$; other scaling relationships have been reported (e.g., Pawlowska and Brenguier 2003; vanZanten et al. 2005), as discussed by Wood (2005a).

measurements for the present case, as measured precipitation rates are small near cloud base, possibly because open cells were poorly sampled at that flight level; radar observations, however, indicate that precipitation in the open cells was likely greatest near cloud base.

We speculate that cloud water sedimentation in the ensemble is sufficiently strong to match the precipitation flux within the open cells in the upper region of the cloud layer, but not enough drizzle is generated in the simulations (at least in terms of horizontal averages) to match the average precipitation flux measured within the open cells below cloud base. A consequence of the lack of heavy drizzle in these simulations is that we are unable to use the ensemble to evaluate the testable hypothesis of Stevens et al. (1998).

The total fluxes of $\theta_{l}$ and $q_{t}$ in Fig. 3 include not only advective and subgrid-scale fluxes but also precipitation, and in the case of $\theta_{l}$, radiation as well; fluxes associated with large-scale subsidence are neglected. The spread in the ensemble is substantial, as are the differences between closed and open cells. The middle half of the ensemble resembles the observations in closed cells more than in open cells, except for the $q_{t}$ flux in the upper region of the cloud, reminiscent of the precipitation 

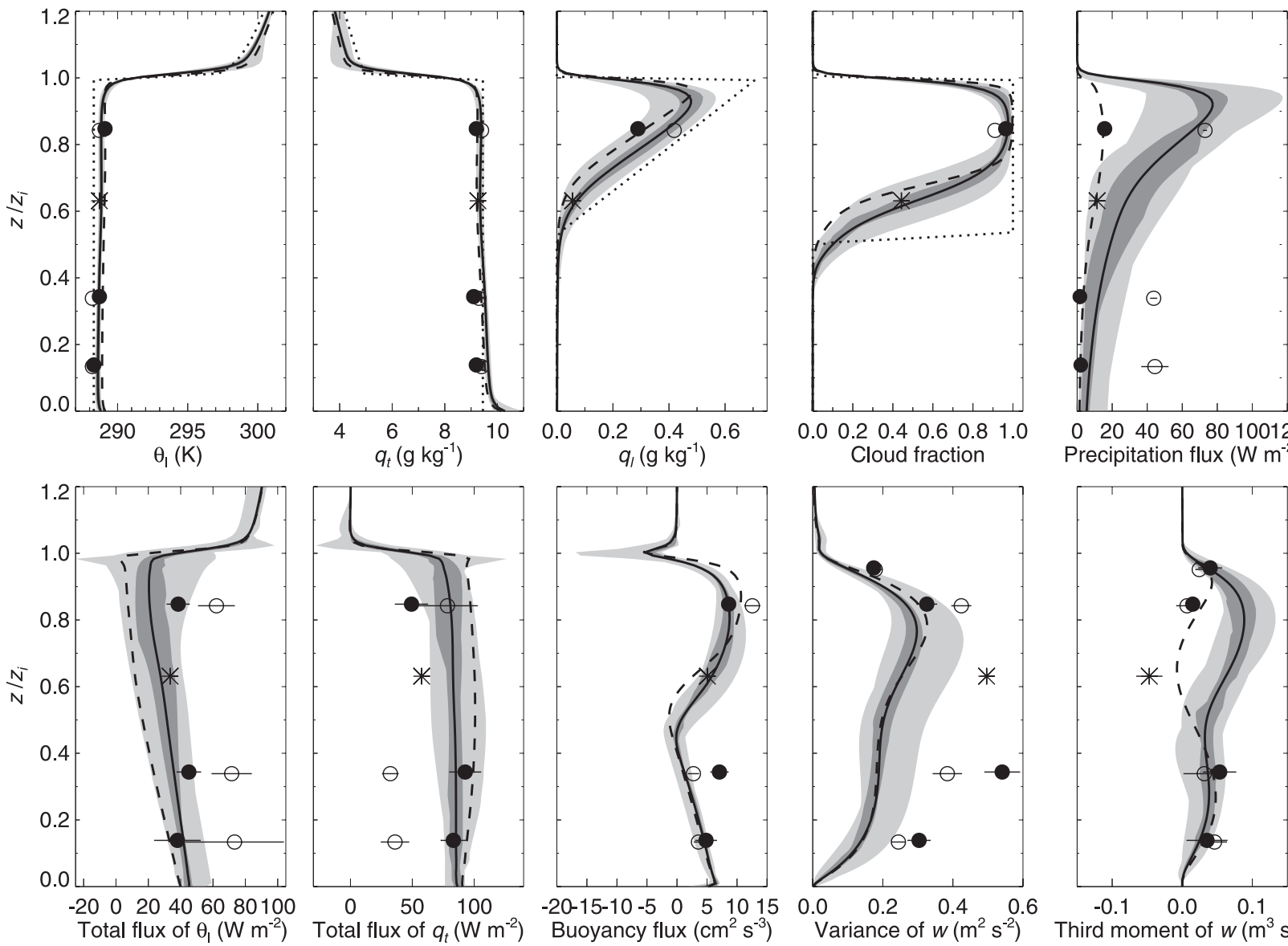

0 20406080100120 Precipitation flux $\left(\mathrm{W} \mathrm{m}^{-2}\right)$

\begin{tabular}{|c|c|c|c|c|c|}
\hline initial & $\overline{\text { ensemble mean }}$ & $\begin{array}{l}\overline{\text { w/o cloud water sedimentation }}\end{array}$ & $\begin{array}{c}O \\
\text { open cells }\end{array}$ & closed cells & $\begin{array}{c}* \\
\text { mixed }\end{array}$ \\
\hline
\end{tabular}

FIG. 3. Ensemble profiles of $\theta_{l}, q_{t}, q_{l}$, cloud fraction (defined in appendix C), precipitation, total flux of $\theta_{l}$ (including precipitation and radiation), total flux of $q_{t}$ (including precipitation), buoyancy flux, $\overline{w^{\prime 2}}$, and $\overline{w^{\prime 3}}$ all averaged over last $4 \mathrm{~h}$ of simulations that include cloud water sedimentation and drizzle. Ensemble range, middle half, and mean denoted by dark and light gray areas and solid lines, respectively. Ensemble mean from simulations that include drizzle but not cloud water sedimentation denoted by dashed lines. Dotted lines denote initial conditions. Measurements shown as open and filled circles for regimes classified as open and closed cells; near cloud base, averages encompass both regimes and are plotted as asterisks because of possible undersampling of open cells at that flight level (vanZanten and Stevens 2005). Horizontal bars are \pm 1 standard deviation. Vertical axis is altitude normalized by inversion height, in which normalization is first done for each half-hourly profile and then interpolated to a uniform grid.

comparison. Beyond that exception, the ensemble does not envelop the total fluxes measured in the open cells, consistent with the underprediction of precipitation below cloud. To the degree that the mean profiles of these total fluxes are linear within the boundary layer, they are consistent with a quasi-steady-state boundary layer in which the shapes of the $\theta_{l}$ and $q_{t}$ profiles are steady, since the divergence of a linear flux profile is independent of height. Consistent with the evolution of the $\theta_{l}$ and $q_{t}$ profiles, the gradient of the ensemble mean $\theta_{l}$ flux implies a boundary layer that is warming, and the lack of gradient in the mean $q_{t}$ flux implies a boundary layer neither drying nor moistening on average, although there is a hint of an implied moistening tendency approaching cloud top.

The middle half of the buoyancy flux distribution is more consistent with the measurements in the closed cells within the cloud, but closer to the measurements in the open cells just below cloud, which is essentially the opposite relationship between simulated and observed precipitation fluxes with respect to open and closed cells. (For brevity we refer to buoyant production of TKE throughout as a buoyancy flux, though it is actually a buoyancy flux times $g / \rho$, where $g=9.8 \mathrm{~m} \mathrm{~s}^{-2}$.) Only in the lower quartile of the ensemble are the timeaveraged buoyancy fluxes negative below cloud base, 


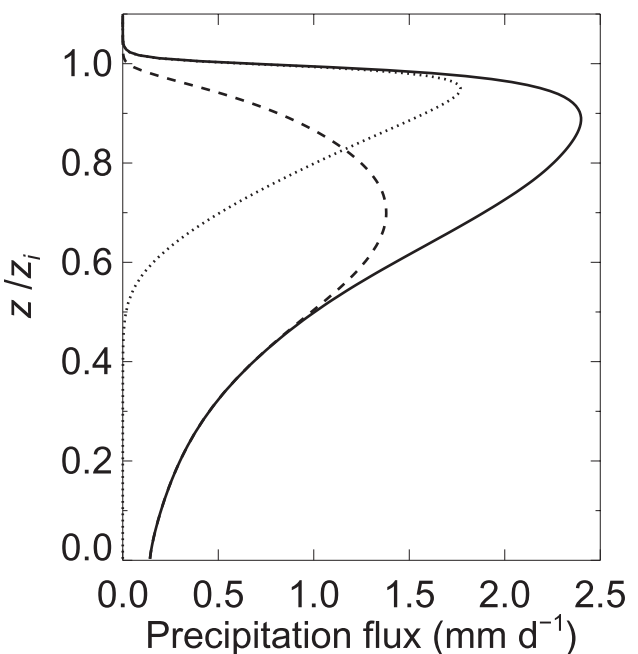

\begin{tabular}{lll}
\hline$\cdots \cdot \cdots$ & $--\overline{-}$ & \\
small drops & large drops & all drops
\end{tabular}

FIG. 4. Precipitation flux profile averaged over last four hours of DHARMA simulation. Dotted and dashed lines are for drops smaller and larger than $25-\mu \mathrm{m}$ radius, respectively, and solid line includes all drops.

a condition associated with decoupling between the cloud and subcloud layers (e.g., Nicholls 1984; Turton and Nicholls 1987).

The $\overline{w^{\prime 2}}$ measurements suggest profiles with a single peak near the middle of the boundary layer. This shape is characteristic of well-mixed boundary layers and is unlike the simulation ensemble, in which $\overline{w^{\prime 2}}$ peaks within the cloud layer and levels off below cloud base. The large values measured at midlevels are well beyond the ensemble range, further suggesting a less convectively mixed boundary layer in the simulations. Stevens et al. (2005b) found a similar result in their comparison of simulations and observations of a boundary layer capped by nonprecipitating stratocumulus. We note that the $\overline{w^{\prime 2}}$ measurements include contributions at scales larger than the 6.4-km-wide model domain, with measurements indicating spectral power of order $10 \%$ of the total at greater scales (Petters et al. 2006).

In the final panel of Fig. 3 it is seen that measured vertical winds are negatively skewed just above cloud base, with downdrafts stronger than updrafts. Negative $w$ skewness in stratocumulus has been reported elsewhere, in field measurements (e.g., Nicholls and Leighton 1986; Stevens et al. 2005b) as well as in model simulations (e.g., Bougeault 1985; Moeng 1986), a topic discussed in detail by Moeng and Rotunno (1990). In contrast, vertical winds are skewed positively in the simulations here, consistent with more cumuliform convection. Omitting cloud water sedimentation results in $\overline{w^{\prime 3}}$ sub- stantially decreased through much of the cloud layer, as discussed further below.

\section{b. Simulations omitting drizzle and cloud water sedimentation}

Before considering the impacts of cloud water sedimentation and drizzle on model results, we first consider simulations omitting both processes. As background, in the stratocumulus simulations of Stevens et al. (2005b), which omitted cloud water sedimentation and drizzle and were based on RF01 of DYCOMS-II, liquid water path within the ensemble ranged from 5 to nearly 60 $\mathrm{g} \mathrm{m}^{-2}$, an order of magnitude in variation. At the low end of the LWP range the models were unable to produce a cloud layer with sufficient radiative cooling to maintain a well-mixed boundary layer. For the two models that produced the thinnest cloud layers (with LWP $<10$ $\mathrm{g} \mathrm{m}^{-2}$ ), the boundary layer radiative cooling was less than $15 \mathrm{~W} \mathrm{~m}^{-2}$, amounting to less than a third of the amount available. Increasing LWP in the ensemble was correlated with convective intensity, as measured by the maximum $\overline{w^{\prime 2}}$, and was inversely correlated with the stratification of boundary layer moisture. Radiative cooling and entrainment tended to increase with LWP, and the ratio of entrainment warming to radiative cooling of the boundary layer was found to be inversely proportional to LWP in the ensemble. That is, simulations that entrained more relative to radiative cooling produced thinner cloud layers.

The meteorological conditions during RF02, which occurred in the same region about $24 \mathrm{~h}$ after RF01, but with slightly cooler, moister air overlying the boundary layer, apparently pose less of a challenge to the models, in that they are all able to maintain a reasonably thick cloud layer that radiatively cools the boundary layer by the full amount available. As seen in Fig. 5, LWP averaged over the last $4 \mathrm{~h}$ of each simulation ranges by less than a factor of 2 here, with the minimum here $30 \%$ greater than the maximum for the RF01 ensemble. As in the RF01 ensemble, the more vigorous, well-mixed boundary layers produce the thickest clouds, as LWP correlates well with the maximum $\overline{w^{\prime 2}}$ and inversely with moisture stratification (as measured by $\delta q_{t}$, the difference in $q_{t}$ between $z / z_{i}=0.25$ and 0.75 ). As in the RF01 ensemble, the minimum buoyancy flux also correlates inversely with the maximum $\overline{w^{\prime 2}}$ and LWP here (not shown).

In contrast to the RF01 ensemble, bulk radiative cooling $\left(\Delta F_{\text {rad }}\right.$ in Fig. 5) is largely independent of LWP here, with all but one case radiatively cooling by $\sim 15 \%$ more than the net $48 \mathrm{~W} \mathrm{~m}^{-2}$ available to the cloud layer. Bulk radiative cooling is computed here as the difference in radiative flux between cloud top (defined by a threshold of $0.01 \mathrm{~g} \mathrm{~kg}^{-1}$ for each $q_{l}$ profile) and the 


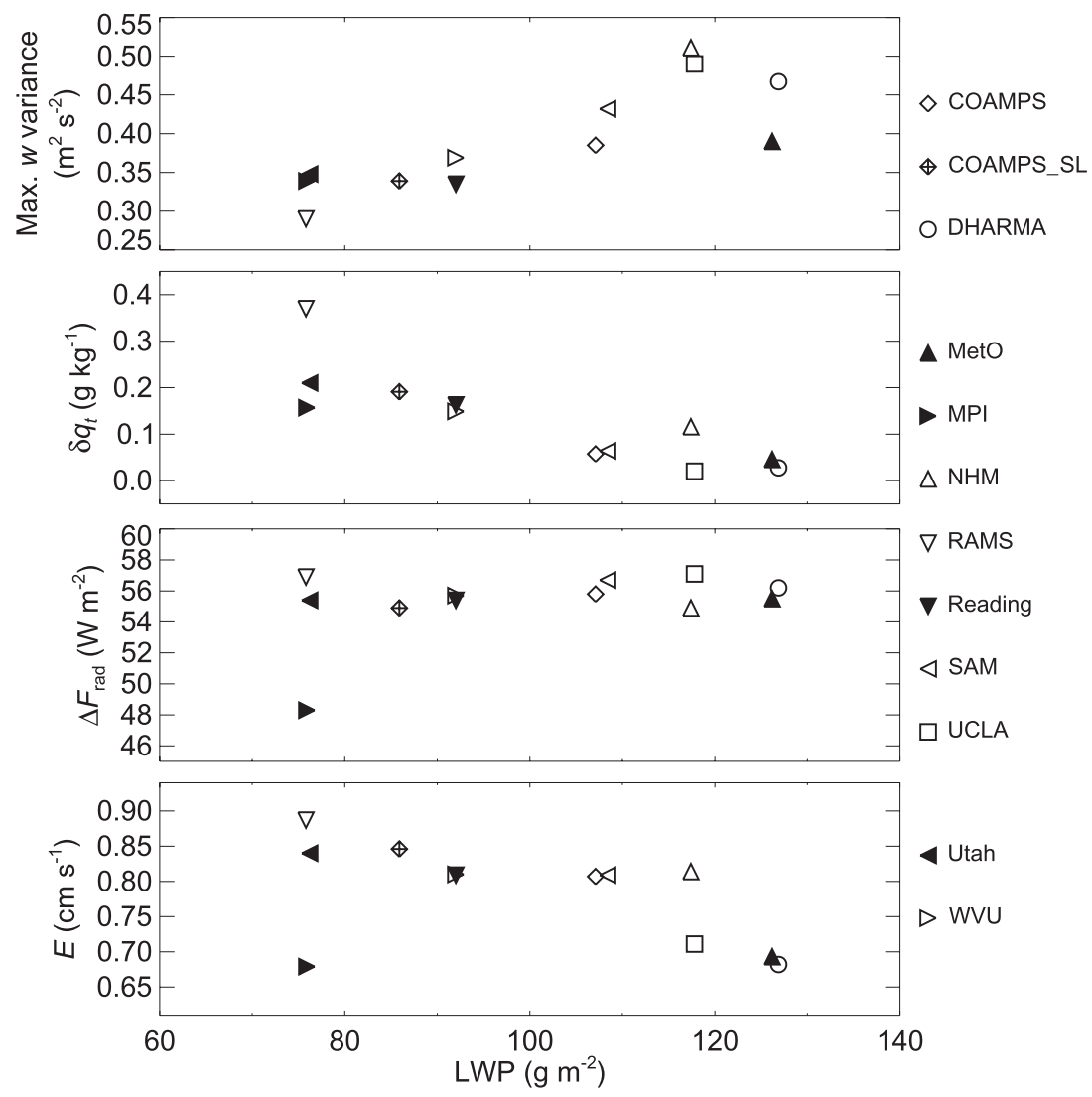

FIG. 5. Maximum $\overline{w^{\prime 2}}$, boundary layer moisture stratification $\left(\delta q_{t}\right)$, bulk radiative cooling $\left(\Delta F_{\text {rad }}\right)$, and entrainment rate $(E)$, all defined in text. Statistics are computed from halfhourly profiles and then averaged over the last $4 \mathrm{~h}$ of simulations that omit cloud water sedimentation and drizzle.

surface. The cooling in excess of the amount available to the cloud layer occurs above $z_{i}$ [from the third term in Eq. (5)], as some cloud tops poke through the $q_{t}=8$ $\mathrm{g} \mathrm{kg}^{-1}$ isosurface that defines $z_{i}$. MPI is an outlier with respect to bulk radiative cooling but not with respect to the distance between cloud top and the inversion (not shown), which clusters between 12 and $16 \mathrm{~m}$ for all the models but RAMS, for which it is $22 \mathrm{~m}$. The reduced cooling for MPI results from a radiative flux gradient within the inversion that is weaker than for the other models, for no discernible reason.

Like the simulations in the upper half of the LWP distribution for the RF01 ensemble, entrainment correlates inversely with LWP here, with the exception of the outlier with anomalously low radiative cooling. Taking the ratio of entrainment warming to radiative cooling cancels the degree to which it is an outlier, and this ratio $(\alpha)$ correlates inversely with LWP here (not shown), as it did for the RF01 ensemble.

As mentioned above, the previous BLCWG study found that models with less subgrid-scale mixing at cloud top yielded lower values of $\alpha$ and were able to maintain thicker cloud layers. A notable difference in the $\alpha$ ranking from the previous study is that MetO was in the upper quartile previously, whereas here it is among the three lowest $\alpha$ values, joining UCLA and DHARMA, the models with the two lowest $\alpha$ values in the previous study. ${ }^{2}$ The dramatic change in $\alpha$ ranking between the two studies for the MetO model is likely attributable to its using a monotone advection scheme for momentum here, which dampens model energetics at cloud top and thereby reduces entrainment. As in the previous BLCWG intercomparison, when subgrid-scale mixing is increased in the COAMPS model-swapping a prognostic TKE scheme for a diagnostic mixing

\footnotetext{
${ }^{2}$ Stevens et al. (2005b) computed $\alpha$ from terms in a mixed-layer budget analysis, while here we compute it from terms more directly derived from the model diagnostics. Although $\alpha$ values computed through these different methods are not directly comparable, we expect that the relative model rankings by $\alpha$ are at least grossly comparable.
} 
model—entrainment increases and LWP decreases here. Thus, although the air overlying the boundary layer in the present case is somewhat cooler and moister than in the previous study, the relationship between subgridscale mixing, entrainment, and LWP seems to be along the same lines as found previously.

\section{c. Effects of drizzle}

Unlike bin microphysics models, which treat the sedimentation of all condensed water, models that parameterize drizzle have traditionally ignored sedimentation of cloud water. With that legacy in mind, here we first consider a traditional treatment of precipitation for models with parameterized microphysics, through simulations that include drizzle but omit cloud water sedimentation. In the bin microphysics models this is achieved by inhibiting the sedimentation of drops less than $25 \mu \mathrm{m}$ in radius.

Three means by which drizzle is expected to alter boundary layer dynamics and cloud thickness on short time scales (i.e., neglecting constraints imposed by steady-state balance of moisture and heat budgets) are 1) through its removal of condensed water at the surface, 2) through the redistribution of moisture between the cloud and subcloud layers, and 3) through the sedimentation flux divergence within the upper region of the cloud layer. In 1), surface precipitation acts as a sink of moisture and a source of latent heat to the boundary layer, which tend to reduce cloud thickness. In 2), sedimentation of drizzle transports water condensed in the cloud layer into the subcloud layer, where it evaporates, thereby providing a latent heating dipole that warms the cloud layer and cools the subcloud layer. This dipole tends to stabilize the cloud with respect to the subcloud layer, thereby inducing negative buoyancy fluxes near cloud base and reducing boundary layer mixing. As for 3 ), one consequence is that downdrafts may become buoyant above the mean cloud base, thereby reducing boundary layer mixing; another possible consequence is a reduction in moisture available for evaporation in the entrainment zone, thereby reducing entrainment; and another is a weakened $q_{l}$ gradient, thereby decreasing radiative cooling at cloud top and potentially reducing boundary layer mixing. A number of these mechanisms act to reduce boundary layer mixing, which can be expected to result in reduced entrainment, as well. None of the foregoing mechanisms is expected to enhance boundary layer mixing or entrainment. However, decreases in LWP expected from 1) as well as reduced boundary layer mixing could be offset by increases in LWP expected from decreased entrainment.

As seen in Fig. 6, drizzle leads to diminished convective intensity in all the models, and to an increase in stratification of boundary layer moisture and a reduction of the minimum buoyancy flux (between $z / z_{i}=0.25$ and 0.75 ) for all but one model. In the absence of drizzle, the minimum buoyancy flux is positive for the three models with the greatest LWP, and stabilization associated with drizzle evidently induces negative buoyancy fluxes for those models. Reductions in entrainment are seen to be modest throughout the ensemble, and bulk radiative cooling (not shown) changes by less than $1 \mathrm{~W} \mathrm{~m}^{-2}$ in all cases. Although bulk radiative cooling is negligibly affected, drizzle does lead to a reduction in the $q_{l}$ gradient at cloud top and a corresponding reduction in the peak radiative cooling rate there, as shown below.

In all but two cases LWP is reduced by drizzle, suggesting that changes induced by drizzle that tend to decrease LWP dominate those tending to increase it. For only one model (RAMS) does LWP increase substantially, a case in which moisture stratification diminishes and the minimum buoyancy flux increases in response to drizzle. Such an outlying response to drizzle also occurs in the presence of cloud water sedimentation for this model (not shown). Unlike the other models, turbulent mixing above the boundary layer is substantial in the RAMS simulations, and the initial gradients of $\theta_{l}$ and $q_{t}$ above the inversion are nearly eliminated, for no discernible reason. The model produces nearly constant values of $\theta_{l}$ and $q_{t}$ above the inversion that roughly reproduce their initial values at the top of the model domain, resulting in an inversion that is $\sim 2 \mathrm{~K}$ stronger, with overlying air $\sim 1 \mathrm{~g} \mathrm{~kg}^{-1}$ drier than in the other models. Apparently the drier, warmer inversion results in a LWP response to drizzle that is dominated by the reduction in entrainment.

We note that drizzle is quite modest in these simulations, with average rates at the surface no greater than $0.11 \mathrm{~mm} \mathrm{day}^{-1}$ for all but one model, as seen in Fig. 7. As also seen in the figure, there is a tendency for the strongest decreases in LWP to correspond to the strongest surface precipitation. However the overall correlation between drizzle-induced change in LWP and surface precipitation is not strong, with a Spearman rank correlation coefficient of -0.5 , significant at less than a $2-\sigma$ level.

In an intercomparison of single-column models using the same specifications (Wyant et al. 2007), in most cases the entrainment rate either was unchanged or diminished slightly, and LWP decreased substantially in response to including drizzle. The entrainment changes are comparable, and the LWP changes generally greater than found in the LES ensemble here.

In the mixed-layer modeling study of Wood (2007), which omitted cloud water sedimentation, a cloud-base height $\left(z_{b}\right)$ of $400 \mathrm{~m}$ was found to be a threshold in the short-term (12 h) response of LWP to changes in cloud 


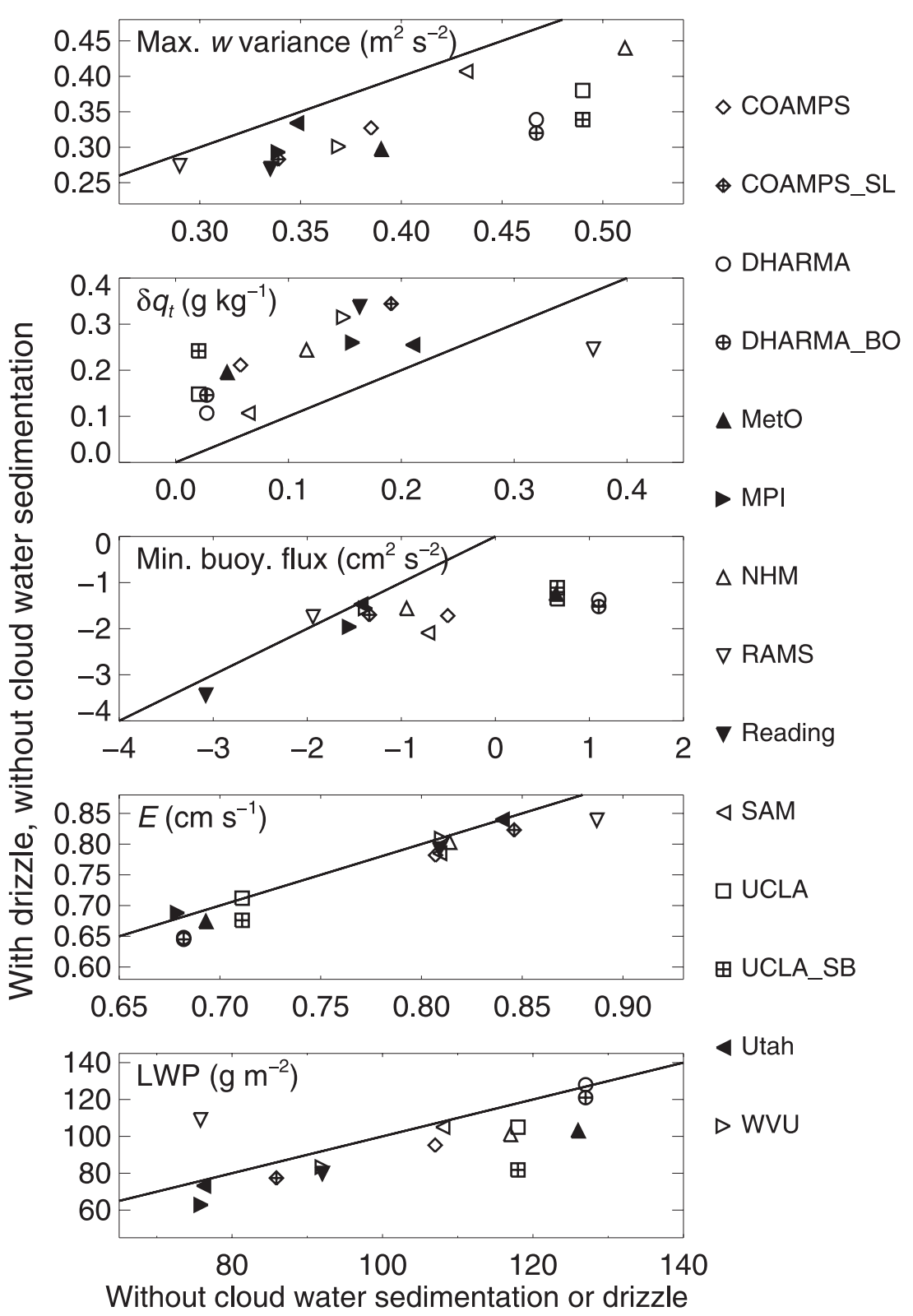

FIG. 6. Maximum $\overline{w^{\prime 2}}$, boundary layer moisture stratification $\left(\delta q_{t}\right)$, minimum buoyancy flux, entrainment rate $(E)$, and LWP, averaged over last $4 \mathrm{~h}$ of simulations that omit drizzle versus those that include it; both sets of simulations omit cloud water sedimentation. Solid lines denote 1:1 relationships. All parameters are defined in the text.

droplet concentration. ${ }^{3}$ For lower or higher cloud bases, LWP increased or decreased, respectively, with $N_{d}$. Thus, for $z_{b}>400 \mathrm{~m}$, the Wood (2007) result indicates LWP increasing in response to including drizzle (equivalent to reducing $N_{d}$ ). Cloud-base heights (defined in

\footnotetext{
${ }^{3}$ The precise response and $z_{b}$ threshold in the mixed-layer model were found to be sensitive to the details of the treatment of evaporation of drizzle in the subcloud layer.
}

appendix C) averaged over the last $4 \mathrm{~h}$ of simulations omitting cloud water sedimentation and drizzle ranges between 500 and $600 \mathrm{~m}$ in nearly all of the simulations here (not shown). In apparent contrast with the mixedlayer model result, LWP decreases in response to including drizzle for nearly all the LES results here. The only model in which LWP substantially increases in response to including drizzle (RAMS) has the highest cloud base, exceeding $600 \mathrm{~m}$, suggesting some consistency with the mixed-layer result. But somewhat 


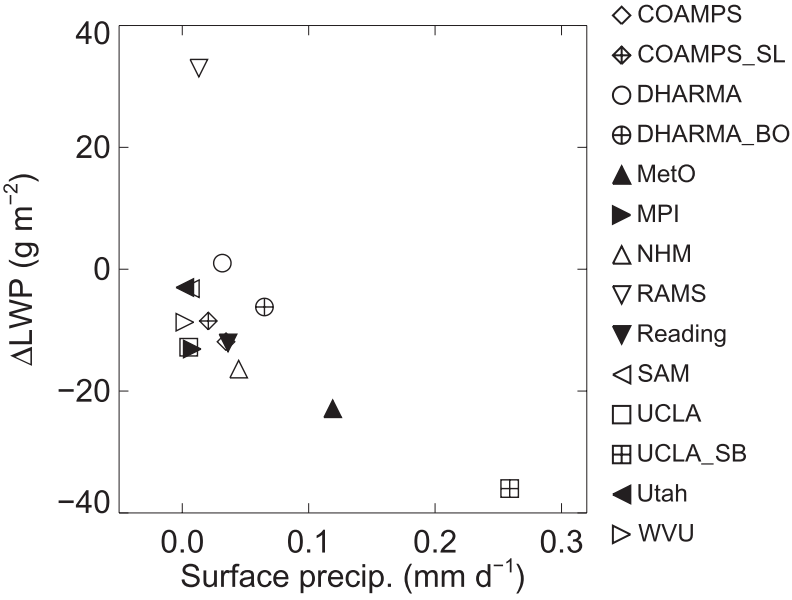

FIG. 7. Surface precipitation rate vs change in LWP associated with drizzle. Results averaged over last $4 \mathrm{~h}$ of simulations, which all omit cloud water sedimentation.

puzzlingly, RAMS produces by far the least well-mixed boundary layer (in terms of moisture stratification) in the simulations without drizzle, and is thus the greatest violator of the fundamental premise of a mixed-layer model, namely, a well-mixed boundary layer. A thorough comparison with Wood (2007) is beyond the scope of this study.

\section{d. Effects of cloud water sedimentation}

In an LES study of changes in LWP induced by increasing aerosol concentrations, Ackerman et al. (2004) noted that with sufficiently dry air overlying the boundary layer the collision-coalescence process effectively shuts down, and that aerosol-induced increases in droplet concentration reduce cloud water sedimentation, thereby increasing entrainment, which leads to reduced LWP in more polluted clouds. The potential buoyancy mechanism of Stevens et al. (1998) was suggested as an explanation for the change in entrainment. Subsequently, Bretherton et al. (2007) conducted large-eddy simulations based on the DYCOMS-II RF01 idealization from the BLCWG intercomparison of Stevens et al. (2005b). Bretherton et al. (2007) omitted drizzle but included cloud water sedimentation with the parameterization developed for this study. They found that while entrainment decreases and LWP increases when cloud water sedimentation is included, cloud water sedimentation reduces the efficiency of entrainment without any associated reduction in convective intensity, as expected if potential buoyancy were responsible for the change in entrainment. Instead, Bretherton et al. (2007) found that cloud water sedimentation resulted in $\overline{w^{\prime 2}}$ increasing throughout much of the boundary layer. Sensitivity tests indicated that associated changes in the profile of radiative cooling, from a weaker $q_{l}$ gradient at cloud top, played a minor role in the reduction of entrainment efficiency.

As already noted, in the ensemble of drizzling simulations for the DYCOMS-II RF02 case here, cloud water sedimentation results in reduced entrainment and increased LWP, consistent with Bretherton et al. (2007). In contrast to that study, here we find that cloud water sedimentation results in reduced convective intensity, as measured by maximum $\overline{w^{\prime 2}}$ (see Fig. 1). Also, cloud water sedimentation results in positive $w$ skewness throughout the cloud layer for most of the ensemble, contrasting with the measurements, in which ${w^{\prime 3}}^{3}$ is much smaller than in the ensemble near the middle of the cloud layer, and negative near cloud base (see Fig. 3).

To isolate the impact of cloud water sedimentation, we first consider nondrizzling DHARMA simulations in which cloud water sedimentation is parameterized using Eq. (7). As expected, the entrainment rate is reduced substantially, from 0.67 to $0.50 \mathrm{~cm} \mathrm{~s}^{-1}$, and LWP increases from 123 to $155 \mathrm{~g} \mathrm{~m}^{-2}$ (all averaged over the last $4 \mathrm{~h}$ ). As seen in Fig. 8, vertical winds are negatively skewed throughout the cloud layer in the simulation without cloud water sedimentation, but including it as prescribed (with $\sigma_{g}=1.5$ ) not only reverses the sign of $\overline{w^{\prime 3}}$ but also reduces $\overline{w^{\prime 2}}$ throughout most of the cloud layer. Thus, the changes associated with cloud water sedimentation in the nondrizzling DHARMA simulations are broadly consistent with the changes in the ensemble of drizzling simulations.

Recalling that the cloud droplet size distribution was specified as overly broad in the parameterization of cloud water sedimentation, we also consider a nondrizzling simulation using a narrower distribution, which nearly halves the sedimentation rate for a given cloud water and droplet number concentration. The resulting entrainment rate is $0.57 \mathrm{~cm} \mathrm{~s}^{-1}$, roughly halfway between that without cloud water sedimentation and that with the broader distribution. As seen in Fig. 8 the effect of reduced cloud water sedimentation on $\overline{w^{\prime 3}}$ in the cloud layer is still significant, with a profile that falls between that without and that with stronger cloud water sedimentation. The reduced cloud water sedimentation has far less impact on $\overline{w^{\prime 2}}$, however, which is nearly identical to that without cloud water sedimentation. The response of buoyancy fluxes to progressively increasing cloud water sedimentation seen in Fig. 8 is in the same sense as found by Bretherton et al. (2007), though considerably stronger here. The contribution of water loading to the buoyancy flux is seen to progressively increase with the strength of the cloud water sedimentation, consistent with the progressively decreasing buoyancy flux within the cloud layer. The progressive increase in 

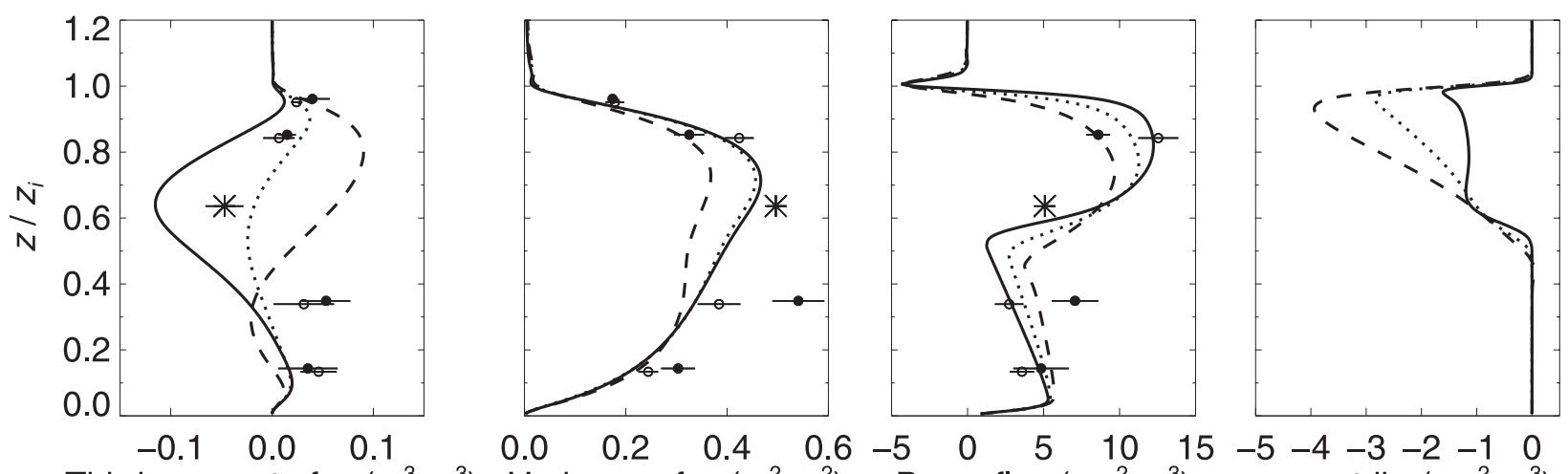

Third moment of $w\left(\mathrm{~m}^{3} \mathrm{~s}^{-3}\right) \quad$ Variance of $w\left(\mathrm{~m}^{2} \mathrm{~s}^{-2}\right) \quad$ Buoy. flux $\left(\mathrm{cm}^{2} \mathrm{~s}^{-3}\right)$

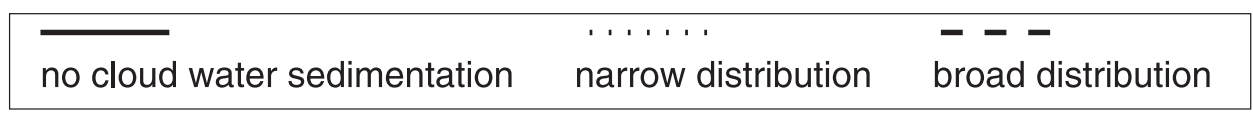

FIG. 8. Third and second moments of vertical wind, the resolved buoyancy flux, and the contribution of water loading to the resolved buoyancy flux $\left(-g w^{\prime} q_{l}{ }^{\prime}\right)$, all averaged over last $4 \mathrm{~h}$ of DHARMA simulations without drizzle. Solid lines are results without cloud water sedimentation, and dotted and dashed lines are results that include parameterized cloud water sedimentation with $\sigma_{g}=1.2$ and 1.5 , respectively. Symbols denote measurements, as in Fig. 3.

the negative contribution of water loading to the buoyancy flux in the upper two-thirds or so of the cloud layer is partly attributable to increases in average $q_{l}$ (seen in Fig. 9), but a greater role is played by increased variance of $q_{l}$ and a redistribution of cloud water from downdrafts into updrafts (not shown). Below $z / z_{i} \simeq$ 0.6 , the changes in buoyancy fluxes are reversed, with buoyancy fluxes becoming progressively stronger with increasing cloud water sedimentation. Bretherton et al. (2007) similarly found that cloud water sedimentation resulted in greater buoyancy fluxes in the lower region of the cloud layer and below, which was attributed to the reduced entrainment of warm, dry air.

Using the environmental conditions of RF01, we find the responses of a nondrizzling DHARMA simulation to cloud water sedimentation to be broadly consistent with those of Bretherton et al. (2007), including enhanced $\overline{w^{\prime 2}}$ throughout most of the boundary layer (not shown). The nonlinear (and reversed) response of $\overline{w^{\prime 2}}$ to cloud water sedimentation in the RF02 simulations occurs in the presence of sedimentation that is much more intense than in the RF01 simulations. In DHARMA simulations without cloud water sedimentation or drizzle, the cooler and moister air overlying the boundary layer results in a peak $q_{l}$ that is $\sim 50 \%$ greater for RF02 than for RF01 conditions, as seen in Fig. 9. Combined with a cloud droplet number concentration in the RF02 case that is less than half the $140 \mathrm{~cm}^{-3}$ average measured during RF01 (vanZanten et al. 2005), the cloud water sedimentation rate near cloud top is nearly quadrupled relative to RF01. As seen in Fig. 9, cloud water sedimentation in the RF02 simulations results in a greater fraction of unsaturated air in the lower reaches of the cloud layer, particularly for $\sigma_{g}=1.5$. In contrast, the fraction of unsaturated air within the cloud layer is largely unaffected by cloud water sedimentation for the RF01 simulations.

Such a drying of the air in the lower region of the cloud layer is expected if the potential buoyancy mechanism of Stevens et al. (1998) is playing a role in these nondrizzling RF02 simulations. In the heavily drizzling simulations of Stevens et al. (1998), the loss of evaporative cooling in the downdrafts is strong enough to result in the net buoyancy flux within the downdrafts becoming negative from the lower half of the cloud layer down nearly to the surface. In these nondrizzling simulations, cloud water sedimentation does lead to significantly reduced buoyancy fluxes in downdrafts within the cloud layer (not shown), but unlike the drizzling case of Stevens et al. (1998), here the reduction does not result in a net negative buoyancy flux when summed over all downdrafts. Thus, while the potential buoyancy mechanism evidently plays a role in reducing convective intensity here, its intensity is considerably weaker than in the heavily drizzling regime of Stevens et al. (1998).

The $q_{l}$ gradient at cloud top is reduced in response to progressively increasing cloud water sedimentation, and as seen in Fig. 9 the reduction is more pronounced in the RF02 simulations. This reduction affects not only the moisture available for evaporation in the entrainment zone but also affects the radiative cooling profile. In the RF01 case, the peak radiative cooling rate decreases by $\sim 5 \%$ in response to cloud water sedimentation with $\sigma_{g}=1.2$ and decreases by that much again as $\sigma_{g}$ is 

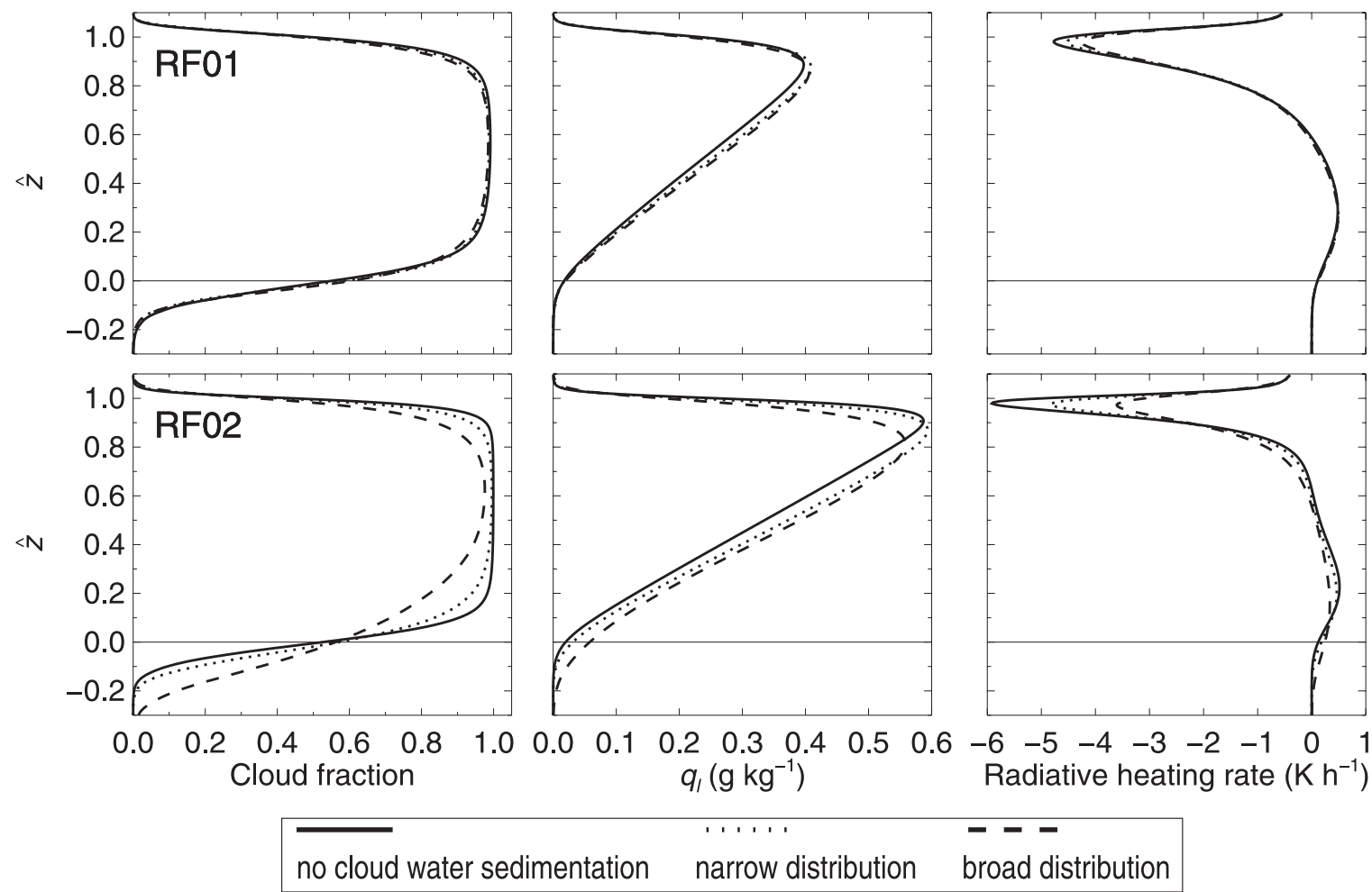

FIG. 9. Profiles of (left) cloud fraction, (center) liquid water mixing ratio, and (right) radiative heating, averaged over last $4 \mathrm{~h}$ of DHARMA simulations without drizzle for (top) RF01 and (bottom) RF02 conditions. Solid lines are results without cloud water sedimentation, and dotted and dashed lines are results that include parameterized cloud water sedimentation with $\sigma_{g}=1.2$ and 1.5 . Vertical coordinate is normalized height between cloud base and inversion. All parameters are defined in appendix C.

increased to 1.5 ; for the $\mathrm{RF} 02$ case the respective reductions are $\sim 20 \%$ and $25 \%$ (Fig. 9). Although the peak cooling rates are reduced by cloud water sedimentation, the net radiative cooling of the cloud layer is unaffected, as the radiative cooling is simply distributed over more depth. Bretherton et al. (2007) found that the change in the radiative cooling profile associated with cloud water sedimentation played a secondary role in reducing entrainment for the RF01 conditions, a conclusion we cannot test with the results here.

Next we consider the role of cloud water sedimentation in the ensemble of drizzling RF02 simulations. As seen in Fig. 10, the responses for nearly all the models are in same sense as found in the nondrizzling DHARMA simulations discussed above: maximum $\overline{w^{\prime 2}}$ and $E$ decrease, while $\overline{w^{\prime 3}}$ near cloud base and LWP increase. The minimum buoyancy flux also increases for all but one model (RAMS), for which it is unchanged (not shown). The changes in boundary layer moisture stratification $\left(\delta q_{t}\right)$, however, are less lopsided: for the four drizzling simulations with the lowest stratification without cloud water sedimentation, $\delta q_{t}$ increases, while for the two with the greatest stratification, $\delta q_{t}$ decreases, and the response is muddled at intermediate values.
Other statistics (not shown) suggest a widespread change to a more cumuliform regime: the relative dispersions (standard deviation divided by the mean) of $z_{i}$, LWP, and $z_{b}$ increase in all cases.

As seen in Fig. 11, drizzle results in a slight increase in the ensemble mean fraction of unsaturated air near cloud base, as expected in the potential buoyancy mechanism (Stevens et al. 1998). Drizzle also leads to a weaker gradient of the ensemble mean $q_{l}$ profile at cloud top, which is expected to result in reduced entrainment efficiency (Bretherton et al. 2007). As a result of the reduced $q_{l}$ gradient at cloud top, the peak radiative cooling rate is also reduced. Consistent with the RF02 nondrizzling DHARMA simulations discussed above, cloud water sedimentation augments these drizzle induced changes, leading to an even weaker $q_{l}$ gradient and peak radiative cooling rate, and resulting in a substantial increase in the fraction of unsaturated air throughout the cloud layer, particularly in the lower third of the cloud layer. (The tendencies in these ensemble mean profiles are also evident in the ensemble median profiles, which are not shown.) Thus, elements of not only the mechanism of Bretherton et al. (2007) associated with cloud water sedimentation, but also the 


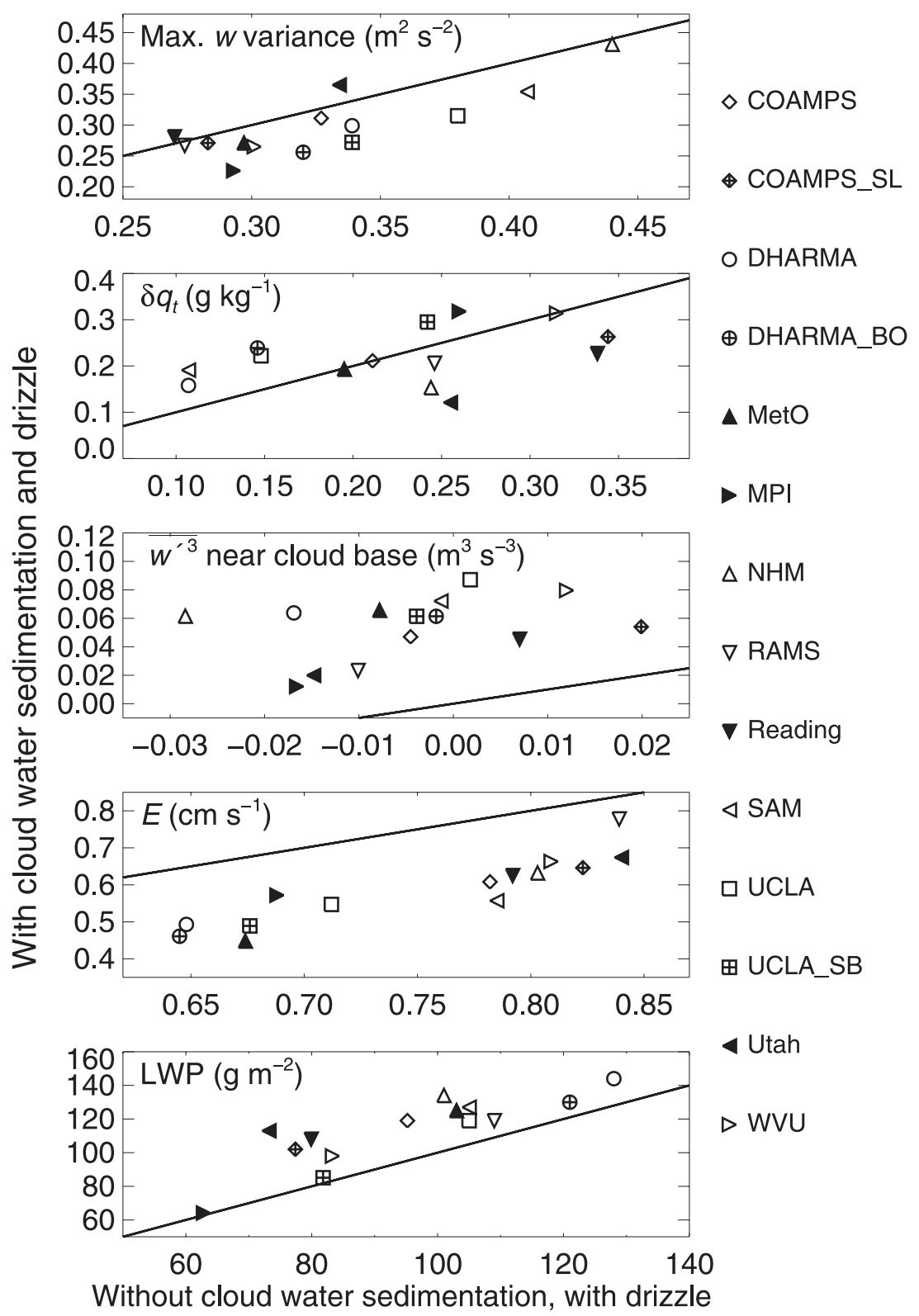

FIG. 10. Maximum $\overline{w^{\prime 2}}$, boundary layer moisture stratification $\left(\delta q_{t}\right), \overline{w^{\prime 3}}$ near cloud base (at $z / z_{i}=0.6$ ), entrainment rate $(E)$ and LWP, averaged over last $4 \mathrm{~h}$ of simulations that omit cloud water sedimentation versus those that include it; both sets of simulations include drizzle. Solid lines denote 1:1 relationships. All parameters defined in the text.

mechanism of Stevens et al. (1998) associated with heavy drizzle, appear to be induced by both drizzle and cloud water sedimentation here. Such commonality is to be expected, since both mechanisms rely on a sedimentation flux divergence in the upper region of the cloud layer, which is provided by drizzle as well as cloud water sedimentation (Fig. 3). As discussed by Bretherton et al. (2007), evaporation of drizzle below the cloud layer drives a significant forcing not provided by cloud water sedimentation, however. Thus, despite the greater impact of cloud water sedimentation on the fraction of unsaturated air within the cloud layer, a comparison of Figs. 6 and 10 indicates that drizzle is more effective here in reducing convective intensity and increasing moisture stratification.

As expected from the ensemble behavior evident in Fig. 1, the decreases in $E$ and increases in LWP resulting from cloud water sedimentation are substantial across 

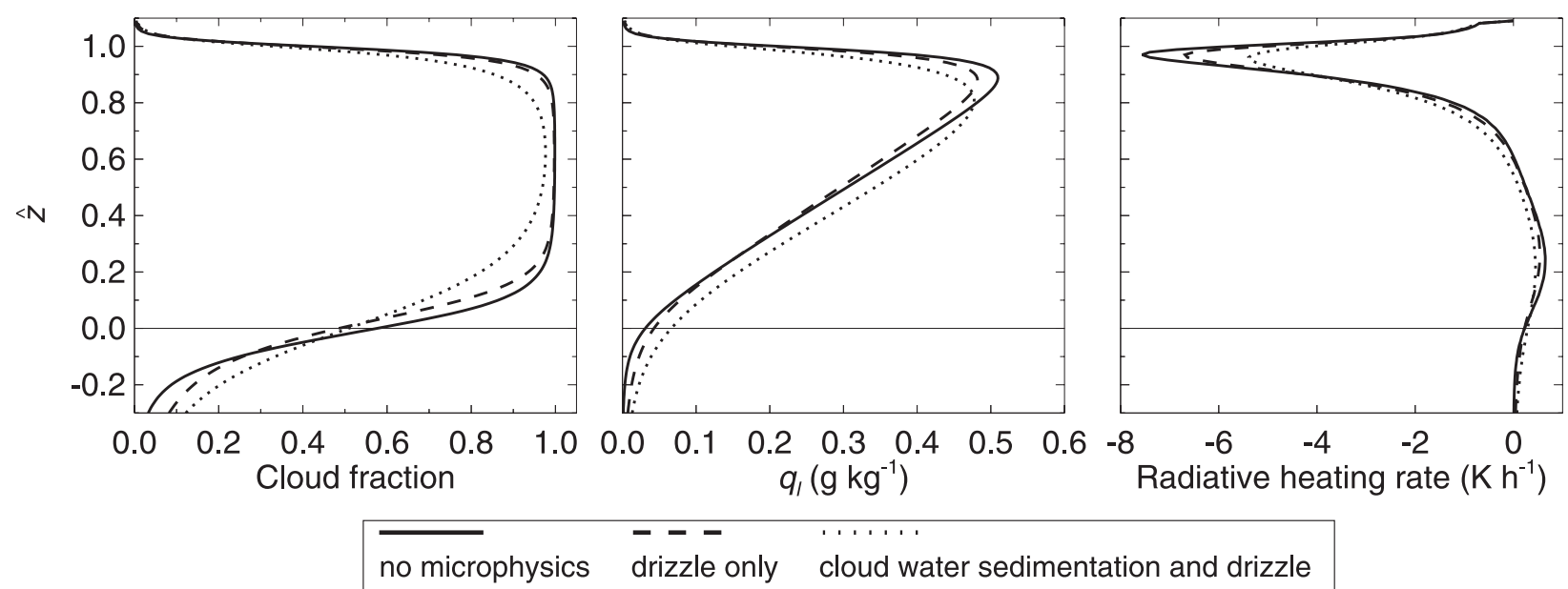

FIG. 11. Profiles of (left) ensemble mean cloud fraction, (center) liquid water mixing ratio, and (right) radiative heating rate, all averaged over last $4 \mathrm{~h}$ of simulations. Solid lines are results without cloud water sedimentation or drizzle, dashed lines are results that include drizzle but omit cloud water sedimentation, and dotted lines are results that include cloud water sedimentation and drizzle. Vertical coordinate is normalized height between cloud base and inversion; normalization done for each member of ensemble separately for each half-hourly average, then averaged together. All parameters defined in the text.

the ensemble, both changes amounting to $\sim 20 \%$ on average. Recall that when a narrower droplet size distribution is assumed for parameterized cloud water sedimentation in the nondrizzling DHARMA simulations, the entrainment rate falls about halfway between that without cloud water sedimentation and that using the specified $\sigma_{g}=1.5$. Thus, for the drizzling simulations with models that parameterize cloud water sedimentation, entrainment rates would likely have been greater and thus LWP likely reduced had a more appropriate value of $\sigma_{g}=1.2$ been specified. Consequently, the middle half of the ensemble likely would have matched the measurements better (see Fig. 1).

It is unlikely, however, that using $\sigma_{g}=1.2$ would have improved agreement between the observations and the ensemble either for maximum $\overline{w^{\prime 2}}$ or for $\overline{w^{\prime 3}}$ near cloud base. An extreme limit of reducing cloud water sedimentation is to omit it entirely, in which case there is no overlap between the ensemble and the measurements of maximum $\overline{w^{\prime 2}}$ (which range from 0.48 to $0.51 \mathrm{~m}^{2} \mathrm{~s}^{-2}$ ) or $\overline{w^{\prime 3}}$ near cloud base $\left(-0.07\right.$ to $\left.-0.03 \mathrm{~m}^{3} \mathrm{~s}^{-3}\right)$ in the simulations with only drizzle (Fig. 10).

It is furthermore unlikely that a smaller value of $\sigma_{g}$ would have improved agreement between the ensemble and the observations of precipitation. As seen in Fig. 12, including cloud water sedimentation as specified results in increased precipitation rates at cloud base and at the surface, and the increases correlate well with the precipitation rates in the absence of cloud water sedimentation. A simple, plausible pathway by which cloud water sedimentation might enhance precipitation is through reduced entrainment leading to increased LWP, which then might result in greater precipitation. We cannot test this hypothesis with the results here, and the actual mechanism may be more complex. Regardless of the details, had $\sigma_{g}=1.2$ been used in the drizzling simulations by the models that parameterize cloud water sedimentation (i.e., all but DHARMA and RAMS), in all likelihood the precipitation would have weakened. If so, the discrepancy in surface precipitation between the observations and the ensemble would have been even greater, and at cloud base fewer members of the ensemble would have overlapped with the range of observations.

We note that in the intercomparison of single-column models using the same specifications (Wyant et al. 2007), LWP was found to increase in response to including cloud water sedimentation, as found here.

\section{e. Combined effects of cloud water sedimentation and drizzle}

When taken together, some of the changes associated with cloud water sedimentation are in the same sense, and some in the opposite sense, as those associated with drizzle. The convective intensity in nearly all the models is reduced by both processes, which thus reinforce each other and result in substantial reductions in the maximum $\overline{w^{\prime 2}}$, as seen in Fig. 13. For a number of models the microphysically induced changes in moisture stratification are opposed, and with the exception of one model (Utah), the offsetting changes are dominated by an increase in $\delta q_{t}$ associated with drizzle. Thus the net effect of including microphysics is a less vigorous, well-mixed boundary layer for nearly all the models. In terms of 


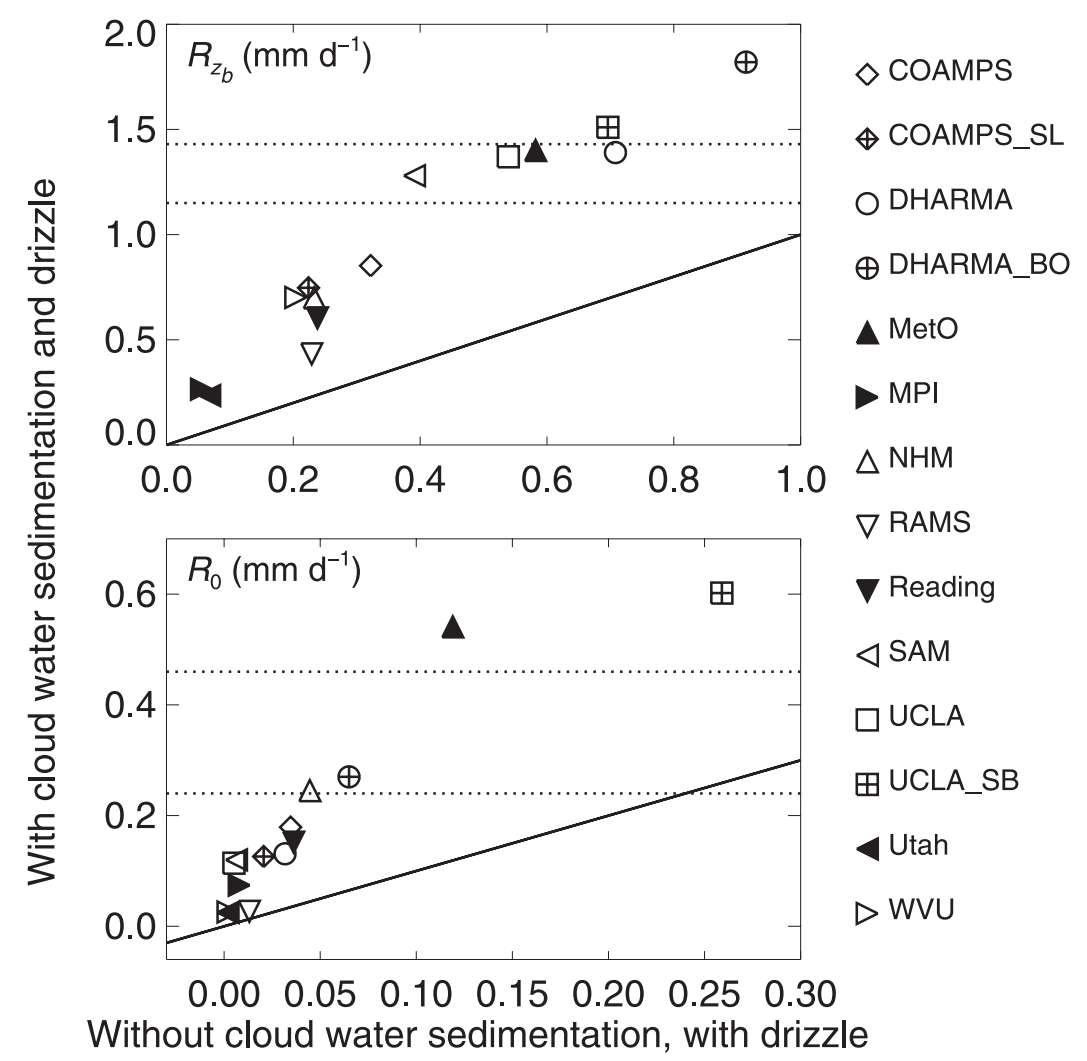

FIG. 12. Precipitation rate at (top) cloud base $\left(R_{z_{b}}\right)$ and (bottom) the surface $\left(R_{0}\right)$ from simulations that omit cloud water sedimentation vs those that include it; both sets of simulations include drizzle. Solid lines denote 1:1 relationships. Dotted lines denote measurement ranges (see Figs. 1 and 2).

entrainment, the microphysically induced changes tend to reinforce each other, resulting in a substantial net reduction. The microphysically induced changes in LWP are largely in opposition, and the impact of cloud water sedimentation dominates for nearly all the models. The two models with a net decrease in LWP are also those with the weakest response of LWP to cloud water sedimentation. One of them (UCLA-SB) has not only the strongest surface precipitation in the ensemble, but also the greatest LWP reduction in response to drizzle. The other (MPI) consistently produces the least LWP.

Although the microphysically induced changes in LWP and moisture stratification are diverse, together they are inversely well correlated, as seen in Fig. 14. This inverse correlation is indicative of the tendency for wellmixed boundary layers to maintain thicker cloud layers. For reasons unclear to us, however, there is an offset in the seemingly linear relationship between the microphysically induced changes, such that small-to-middling LWP increases occur jointly with small-to-middling increases in moisture stratification. We note that although the changes in LWP and $E$ correlate well in response to cloud water sedimentation when drizzle is omitted, for all other microphysical combinations there is little correlation between the changes in LWP and $E$ (not shown).

The final panel of Fig. 13 shows that the ratio of entrainment warming to radiative cooling for the simulations without microphysics is highly correlated with $\alpha$ values in the simulations with both microphysical processes included, with a Spearman rank correlation coefficient of 0.86 that is significant at a $3-\sigma$ level. To the degree that $\alpha$ encapsulates leading-order terms in the dynamics of the stratocumulus-topped boundary layer, this strong correlation indicates that differences in microphysics among this ensemble are dominated by differences in model dynamics. ${ }^{4}$ Similarities among microphysical approaches are apparently swamped by differences in model dynamics, as evident in the separate poles inhabited by the two models that use bin microphysics. One of them (RAMS) corresponds to the model with the highest value of $\alpha$, with and

\footnotetext{
${ }^{4}$ We caution that this is not to say that differences attributable to microphysics are minor, as the UCLA and DHARMA results indicate that microphysics variations do substantially affect some aspects of the results.
} 


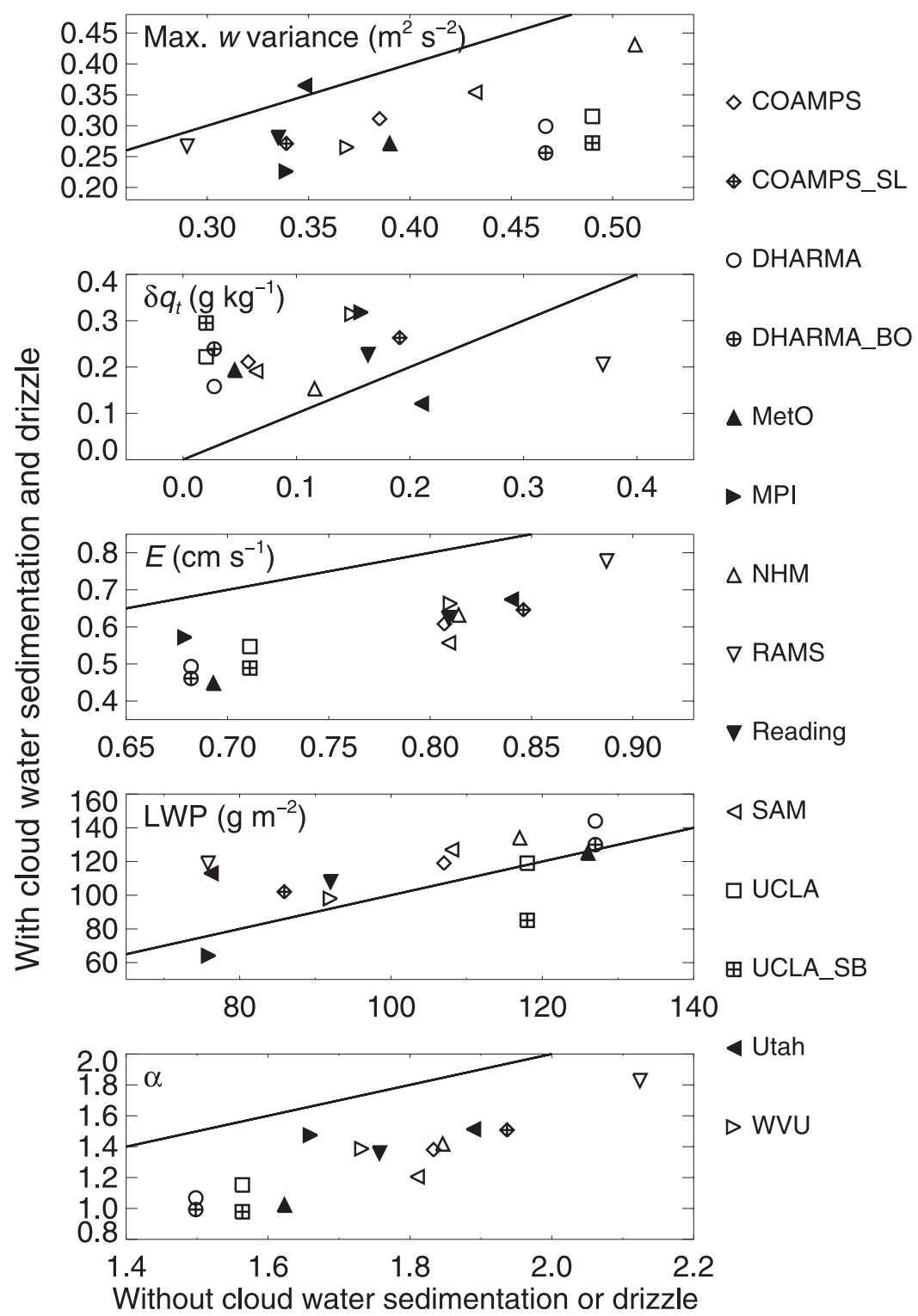

FIG. 13. Maximum $\overline{w^{\prime 2}}$, boundary layer moisture stratification $\left(\delta q_{t}\right)$, entrainment rate $(E)$, LWP, and ratio of entrainment warming to radiative cooling $(\alpha)$, all averaged over the last $4 \mathrm{~h}$ simulations that omit drizzle and cloud water sedimentation versus those that include both processes. Entrainment warming is computed as $\rho c_{p} E \Delta \theta_{l}$, where $\rho$ is the average air density within the boundary layer (between the surface and $z_{i}$ ) and $\Delta \theta_{l}$ is the difference between $\theta_{l}$ at $z=z_{i}+50 \mathrm{~m}$ and its average within the boundary layer; radiative cooling is $\Delta F_{\text {rad. }}$ Solid lines denote 1:1 relationships. All other parameters defined in the text.

without microphysics; while the other (DHARMA) is in a cluster with the smallest $\alpha$ values, with and without microphysics.

\section{Discussion}

In the previous BLCWG intercomparison (Stevens et al. 2005b), it was found that the simulated entrain- ment rates in most of the ensemble were at least $\sim 20 \%$ greater than the measured estimate of $0.38 \mathrm{~cm} \mathrm{~s}^{-1}$ (Stevens et al. 2003b), and the greatest LWP values in the ensemble approached the adiabatic value of $\sim 60$ $\mathrm{g} \mathrm{m}^{-2}$ using the initial conditions. A rough upper range on the observations can be derived from the cloud thickness and maximum $q_{l}$ provided in the supplemental material of Stevens et al. (2003a), indicating LWP 

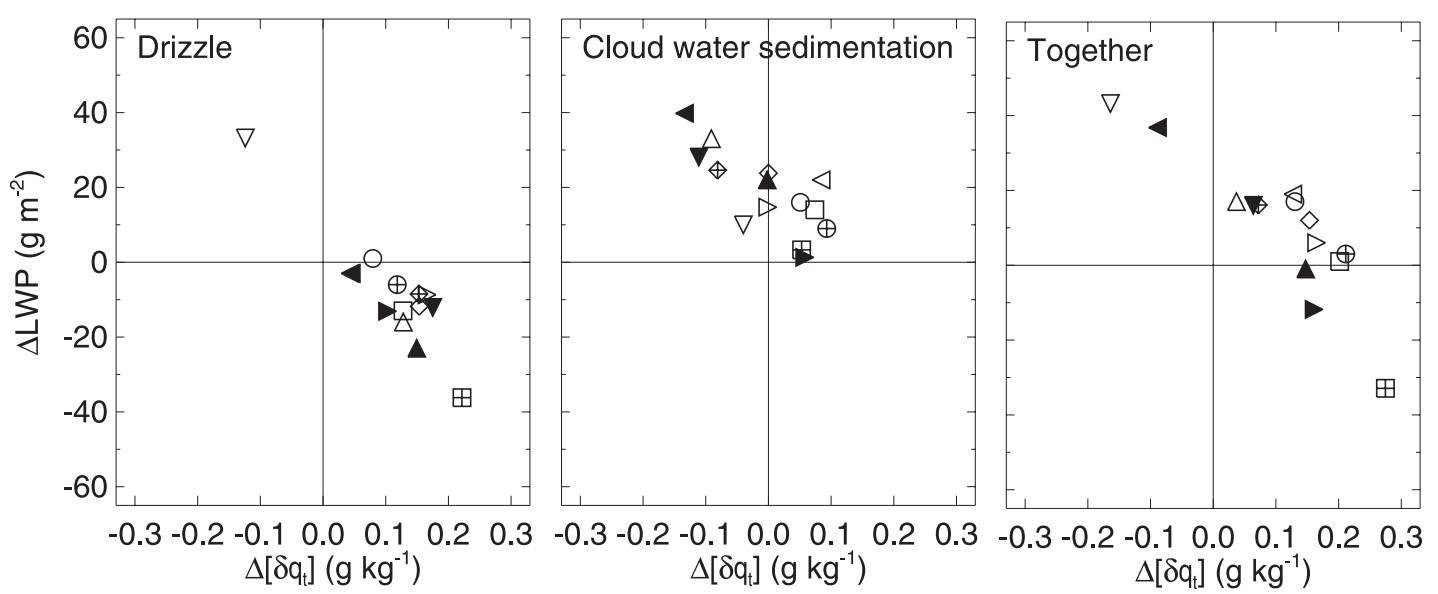

$\diamond$ COAMPS $\diamond$ COAMPS_SL ODHARMA $\oplus$ DHARMA_BO

$\Delta$ MetO $\rightarrow \mathrm{MPI}$ $\triangle \mathrm{NHM}$ $\nabla$ RAMS $\nabla$ Reading $\triangleleft S A M$ $\square$ UCLA 田UCLA_SB

4 Utah $\triangleright$ WVU

FIG. 14. Change of LWP versus change of boundary layer moisture stratification $\left(\delta q_{t}\right)$ associated with (left) drizzle, (center) cloud water sedimentation, and (right) both, all averaged over last $4 \mathrm{~h}$ of simulations. (left) Differences are taken between simulations that include only drizzle and those that omit it (omitting cloud water sedimentation in both cases); (center) differences are taken between simulations that include both microphysical processes and those that include only drizzle; (right) differences are taken between simulations that include and those that omit both.

$\sim 50 \%$ greater. The evidence thus suggests a consistent story of too much entrainment and too little LWP compared to the measurements in that intercomparison, in which it was concluded that progress was needed to limit entrainment through reduced subgrid-scale mixing at cloud top. We note, however, that cloud water sedimentation was not considered in the previous intercomparison. And while the models that parameterize the process here exaggerate its intensity because an overly broad cloud droplet size distribution was used, there is no reason to doubt that cloud droplets fall relative to the air, or that this process leads to reduced entrainment, or that reduced entrainment leads to greater LWP under dry inversions. The results of nondrizzling RF01 simulations, both here and in Bretherton et al. (2007), suggest that some of the systematic overprediction of entrainment and underprediction of LWP in the previous intercomparison likely resulted from omitting this simple physical process. Which is not to claim that the systematic errors in the treatment of subgrid-scale mixing at cloud top, as discussed by Stevens et al. (2005b), do not generally play an even greater role in the overprediction of entrainment. (As a caveat, we cannot rule out the possibility that an inability to resolve entrainment processes at cloud top produces artifacts in the response of entrainment to a sedimentation flux divergence at cloud top.) It seems nonetheless clear that cloud water sedimentation should not be omitted from simulations of stratocumulus, as has been long done by models that parameterize cloud microphysics. Also, it is likely that this process is important to other cloud types, and presumably the lesson carries over to the treatment of cloud ice in mixed-phase and cirrus clouds. ${ }^{5}$ Unfortunately the treatment of cloud water sedimentation introduces further parameters to the microphysical mix. Assuming a lognormal cloud droplet size distribution introduces two additional parameters: total number concentration and the geometric standard deviation, treated here as constants.

It is puzzling that the simulation ensemble here overlaps with the observed entrainment rate and LWP so well, while missing the shape and peak value of the measured $\overline{w^{\prime 2}}$ profile by so much. Considering the number of observationally derived constraints used in the simulation specifications, together with the feedbacks between boundary layer dynamics and cloud properties, one might have expected to roughly match either all three of these observational targets or none of them. The implications of this apparent paradox are unclear, but they might be discouraging from the perspective of using field measurements to evaluate the fidelity of model simulations, or of using large-eddy simulations to calibrate entrainment closures in simpler models.

The suitability of the observed system for evaluating model fidelity is worth pondering here. One of our goals was to evaluate which microphysical schemes might best reproduce the observed drizzle profile. Yet the choice of

\footnotetext{
${ }^{5}$ Although long omitted from cloud-resolving models, sedimentation of cloud water and cloud ice have been incorporated into a general circulation model recently (Boville et al. 2006) and assumptions regarding size distributions of cloud ice shown to substantially effect the abundance of cirrus clouds and associated radiative processes (Mitchell et al. 2008).
} 
a case study was less than ideal, if for no other reason than the considerable heterogeneity of the observed cloud field, a bimodal population of open and closed cells, the former drizzling heavily and the latter far less so. In retrospect, an idealization of their average is a problematic target for models. As noted earlier, given the nonlinearity of the drizzle process with respect to $N_{d}$ and LWP, results of such a comparison are likely to be unfavorable even if the models and measurements are perfect. A more homogeneous cloud field would be a better target. With regard to drizzling stratocumulus, the seventh research flight of DYCOMS-II would seem to be a promising candidate.

Beyond such difficulties intrinsic to this case study, one can further ask if the fidelity of the representation of any single process can truly be isolated in such an approach. For instance, given measurements of a more homogeneous cloud field, would there be a better prospect of determining which microphysics schemes best represent drizzle? Considering that differences in simulations result from a complex mix of all the model subcomponents, it is difficult to be optimistic in this regard. It might have been expected that, by virtue of a common approach, the two models with bin microphysics (DHARMA and RAMS) would have distinguished themselves from the rest. But a number of diagnostics indicate just the opposite, as any commonality in microphysical approach between these two models is clearly swamped by differences in dynamics. A more fruitful approach might be to swap a model subcomponent of interest (such as microphysics) among an assortment of models to see if any tended to produce results more faithful to some sample of case studies that are well constrained and lacking obvious deficiencies.

\section{Summary}

We have compared large-eddy simulations based on an idealization of the second research flight (RF02) of the DYCOMS-II field project, which sampled a bimodal population of heavily drizzling pockets of open cellular convection amid lightly drizzling, overcast stratocumulus. Results of 6-h nocturnal simulations from 11 groups were used. Two models used bin microphysics schemes, which resolve the size distributions of aerosol and cloud particles and explicitly treat cloud microphysical processes. The remaining models fixed the cloud droplet concentration and parameterized drizzle microphysics by a variety of schemes. A simple parameterization of cloud water sedimentation was devised for those models, and simulations were run with and without drizzle, each with and without cloud water sedimentation. Additionally, two of the groups considered variations in the efficiency of drizzle production. The analysis focused on the final 4-h of the simulations. Our principal findings follow.

- The mean liquid water path (LWP) of the ensemble of simulations with cloud water sedimentation and drizzle reproduces the observed mean LWP observation remarkably well, but the mean entrainment rate is at the lower end of the observations, and the ensemble-average maximum vertical wind variance is roughly half that measured.

- In the simulations with cloud water sedimentation and drizzle, precipitation at the surface and at cloud base is smaller on average, and the rate of precipitation evaporation greater, than measured.

- The mean third moment of the vertical wind was observed to be negative near cloud base, indicating downdrafts stronger than updrafts; in contrast, $\overline{w^{\prime 3}}$ is positive near cloud base in the simulations with cloud water sedimentation and drizzle. Cloud water sedimentation leads to increased $\overline{w^{\prime 3}}$ near cloud base for all the simulations with drizzle, thereby reducing agreement with the observations.

- Agreement between observed and simulated entrainment and LWP is much better than in the RF01 model intercomparison, in which models in the tail of the ensemble distribution were unable to maintain a cloud layer of sufficient thickness to produce enough radiative cooling to sustain a reasonably well-mixed boundary layer. The relative spread of LWP is much tighter in this ensemble, which does not require cloud water sedimentation or drizzle, and instead is accredited to a cooler, moister inversion that is more forgiving with respect to excessive entrainment of inversion air.

- Cloud water sedimentation consistently results in decreased entrainment and increased LWP, as found in other studies. In contrast to RF01 simulations, with a thinner cloud layer and thus a reduced sedimentation flux, convective intensity (in terms of $\overline{w^{\prime 2}}$ ) tends to decrease in response to cloud water sedimentation here.

- Including drizzle leads to a decrease in LWP for nearly all the models, and for most models results in slightly decreased entrainment.

The effects on LWP of cloud water sedimentation and drizzle thus oppose each other in this case, and on average cloud water sedimentation dominates here. Drizzle is not all that strong in the simulations, which serves to favor the dominance of the LWP impact of cloud water sedimentation. We strongly recommend against ignoring sedimentation of cloud water, as has long been done in simulations of nonprecipitating as well as precipitating clouds. 
Acknowledgments. We thank Ann Fridlind for helpful discussions, and Robert Wood, David Mecham, and an anonymous reviewer for useful questions and comments. Ackerman was supported by NASA's Radiation Sciences program, Stevens and Savic-Jovcic were supported by National Science Foundation (NSF) Grants ATM-0342625 and ATM-9985413, Khairoutdinov was supported by Department of Energy Grant DE-FG0202ER63370 to Colorado State University as part of the Atmospheric Radiation Measurement Program, Krueger and Zulauf were supported by NSF Grant ATM-0346854, and Petters and Snider were supported by NSF Grants ATM-0103951 and ATM-0602000. Resources supporting this work were provided by the NASA High-End Computing (HEC) Program through the NASA Advanced Supercomputing (NAS) Division at Ames Research Center.

\section{APPENDIX A}

\section{Aerosol Size Distributions}

The bin microphysics models (DHARMA and RAMS) treat aerosols diagnostically (see Stevens et al. 1996). There was considerable variability in the aerosol size distributions measured during RF02, not only between the regions of open and closed cells, but also between the boundary layer and the overlying air. We ignore that complexity and specify a uniform aerosol distribution, obtained by subjectively matching the aerosol size distribution obtained during $30 \mathrm{~min}$ of flight below cloud base (Fig. A1) with two lognormal size distributions assumed to consist of ammonium bisulfate (with molecular weight $115 \mathrm{~g} \mathrm{~mol}^{-1}$, dry density $1.78 \mathrm{~g} \mathrm{~cm}^{-3}$, and two ions dissolved per molecule). The total number, mode radius, and geometric standard deviation for the two modes are 125 and $65 \mathrm{~cm}^{-3}, 0.011$ and $0.06 \mu \mathrm{m}$, and 1.2 and 1.7, respectively. The coincident measurements of cloud condensation nuclei $(\mathrm{CCN})$ performed by the University of Wyoming (Snider et al. 2006) are seen in the right panel to agree with the cumulative $\mathrm{CCN}$ distribution based on the measured size distribution and assumed chemical composition of the aerosol. For the sake of reducing differences between models, aerosol numbers were repartioned between the two modes through trial and error, such that the average cloud droplet number concentration in cloudy grid cells roughly matches the fixed value of $55 \mathrm{~cm}^{-3}$ used by models without bin microphysics. This adjustment was not substantial for DHARMA, with total aerosol numbers set to 115 and $75 \mathrm{~cm}^{-3}$ in the small and large modes, respectively.

\section{APPENDIX B}

\section{Model Descriptions}

Nearly all the models solve equations for $u, v, w, \theta_{l}$, and $q_{t}$ (or specific humidity in some models) in three dimensions; the COAMPS, NHM, MetO, and University of Reading models carry different temperature or moisture variables, as described below. For simulations that omit drizzle, $q_{c}$ is computed diagnostically by assuming that moisture in excess of saturation condenses. Additional microphysical variables for computing drizzle vary among the models, and are described below. All the models treat state variables as uniform within a grid cell, except for WVU, which treats fractional cloudiness within grid cells. All except NHM, RAMS, and the University of Utah models invert Poisson equations to maintain continuity, uniformly based on fast Fourier transforms in the horizontal and an inversion of a tridiagonal matrix (in Fourier space) in the vertical.

The 3D mesh was specified to be $128 \times 128$ in the horizontal with uniform spacing of $50 \mathrm{~m}$ and cyclic boundary conditions. The vertical grid (Fig. B1) was specified as 96 layers with layer thickness $\Delta z=5 \mathrm{~m}$ near the surface, a $\sin ^{2}$ stretching within the boundary layer (with a maximum $\Delta z=25.2 \mathrm{~m}$ at $z=400 \mathrm{~m}$ ), and a $125-\mathrm{m}$ deep region with $\Delta z=5 \mathrm{~m}$ starting at $z=795 \mathrm{~m}$, with $\Delta z$ stretching above to a maximum of $81.4 \mathrm{~m}$ at $z=1500 \mathrm{~m}$, the top of the domain. (A preliminary grid, which did not include the uniform region of 5-m spacing above the inversion, resulted in a positive feedback in which entrainment increased with grid spacing above the initial inversion.) All of the models used the specified grid, except for MPI, which used a uniform $\Delta z=5 \mathrm{~m}$, and RAMS, which used $\Delta z=10 \mathrm{~m}$ up to $z=950 \mathrm{~m}$ and stretching above. It was recommended to translate model domains at a velocity corresponding to the boundary layer mean wind of $(u, v)=(5,-5.5) \mathrm{m} \mathrm{s}^{-1}$ to minimize numerical errors associated with advection. A sponge layer was recommended to dampen any trapped buoyancy waves above the inversion, with a nudging coefficient increasing with $\sin ^{2}$ vertical dependence from 0 at $z=1250 \mathrm{~m}$ to $(100 \mathrm{~s})^{-1}$ at the top of the domain. Brief descriptions of the model configurations used in the intercomparison follow.

\section{a. COAMPS}

Solutions provided by J.-C. Golaz. The LES version of COAMPS ${ }^{\mathrm{B} 1}$ is described in Golaz et al. (2005). With the exception of pressure solver, model dynamics are

\footnotetext{
${ }^{\text {B1 }}$ COAMPS is a registered trademark of the Naval Research Laboratory.
} 

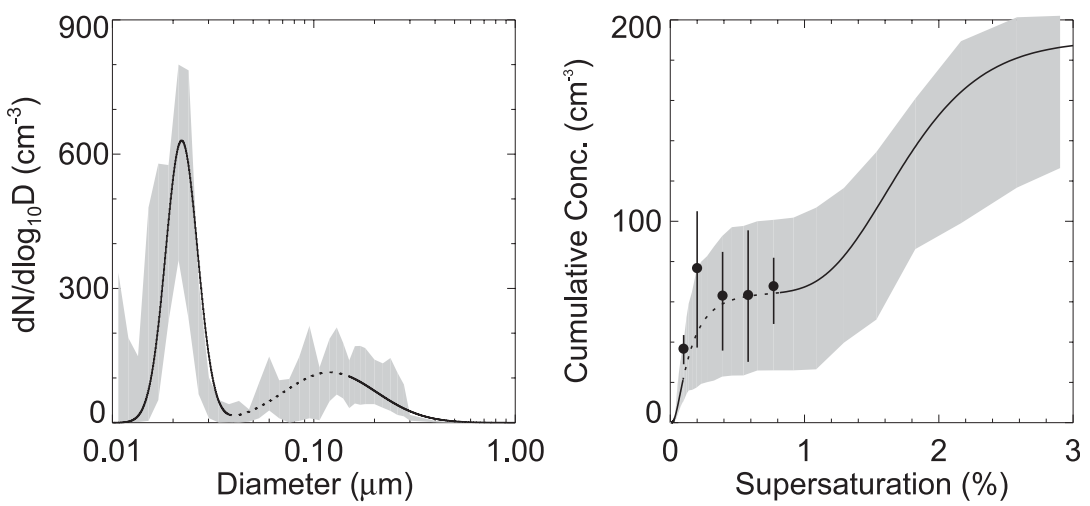

FIG. A1. (left) Differential aerosol size distributions and (right) cumulative CCN spectra. Gray shading shows the range of measured aerosol distributions. Data is from the 1330 to 1400 UTC flight segment below cloud. (left) The black curve is a subjective fit of the size distribution data; (right) the curve shown is the $\mathrm{CCN}$ activation spectrum derived from the fitted size distribution and the ammonium bisulfate parameters discussed in the text. The dotted segment of the curves denotes the range of the fit corresponding to the range of CCN-measured supersaturations. (right) Filled circles are the average CCN measurements and the vertical lines show the range of measured $\mathrm{CCN}$ concentrations.

unchanged from Stevens et al. (2005b); compressible equations have been replaced with anelastic equations. In the default configuration, a prognostic subgrid-scale (SGS) mixing model was used (Deardorff 1980b); results also submitted using a Smagorinsky-Lilly diagnostic treatment, denoted COAMPS SL. The microphysics model, based on Khairoutdinov and Kogan (2000, hereafter KK00), carries potential temperature $(\theta), q_{v}$, $q_{c}, q_{r}$, and number concentration of drizzle drops $\left(N_{r}\right)$ as prognostic variables.

\section{b. DHARMA}

Solutions provided by A. Ackerman. Model dynamics unchanged from DHARMA-0 in Stevens et al. (2005b). A single-moment bin microphysics scheme is used (see Ackerman et al. 2004, and references therein) resolving size distributions of aerosols and activated water drops each into 20 size bins, spanning particle radii of $0.01-2.6$ and $1-260 \mu \mathrm{m}$, respectively. Mass concentration of solute within each drop size bin is carried, doubling the number of microphysical prognostic variables. Drop collision efficiencies follow Hall (1980). Coalescence efficiencies $\left(E_{\text {coal }}\right)$, which follow Beard and Ochs (1984), are extrapolated beyond the measurement range of Beard and Ochs (1984) and limited between 0.5 and unity. An alternative is also considered, denoted DHARMA_BO, in which $E_{\text {coal }}=1$ beyond size range of Beard and Ochs (1984).

\section{c. $\mathrm{Met} O$}

Met Office (MetO) solutions provided by A. Lock. Model dynamics unchanged from Stevens et al. (2005b), except here monotone advection used for all fields, including momentum. Microphysics model carries $q_{v}, q_{c}$, $q_{r}$, and $N_{r}$ as prognostic variables. Autoconversion of $q_{c}$ to $q_{r}$ follows KK00. Fall speed of drizzle drops is an approximate fit to Beard (1976) over a drop radius range of $40-70 \mu \mathrm{m}$.

\section{d. $M P I$}

Max Planck Institute (MPI) solutions provided by A. Chlond. Model dynamics unchanged from MPI-0 in Stevens et al. (2005b), except here the coordinate system is translated with mean geostrophic wind. Microphysics model follows the Lüpkes (1991) three-variable scheme, partitioning condensate into cloud water and rainwater. Here, $N_{r}$ is prognostic, and cloud water content is diagnosed at each time step as the residual between total water content and the saturation vapor content plus the prognostic rainwater.

\section{e. $N H M$}

Non-Hydrostatic Model (NHM) solutions provided by K. Nakamura. The model, developed by the Meteorological Research Institute at the Japan Meteorological Agency, solves fully compressible equations, treating advection with a monotonic centered difference scheme and time stepping with a leapfrog method using an Asselin time filter. Subgrid-scale model is based on Klemp and Wilhelmson (1978) and Deardorff (1980b). Microphysics model carries $\theta, q_{v}, q_{c}$, and $q_{r}$ as prognostic variables. The least aggressive autoconversion scheme used by Richard and Chaumerliac (1989), referred to therein as BR2, is used here. Accretion of cloud droplets 


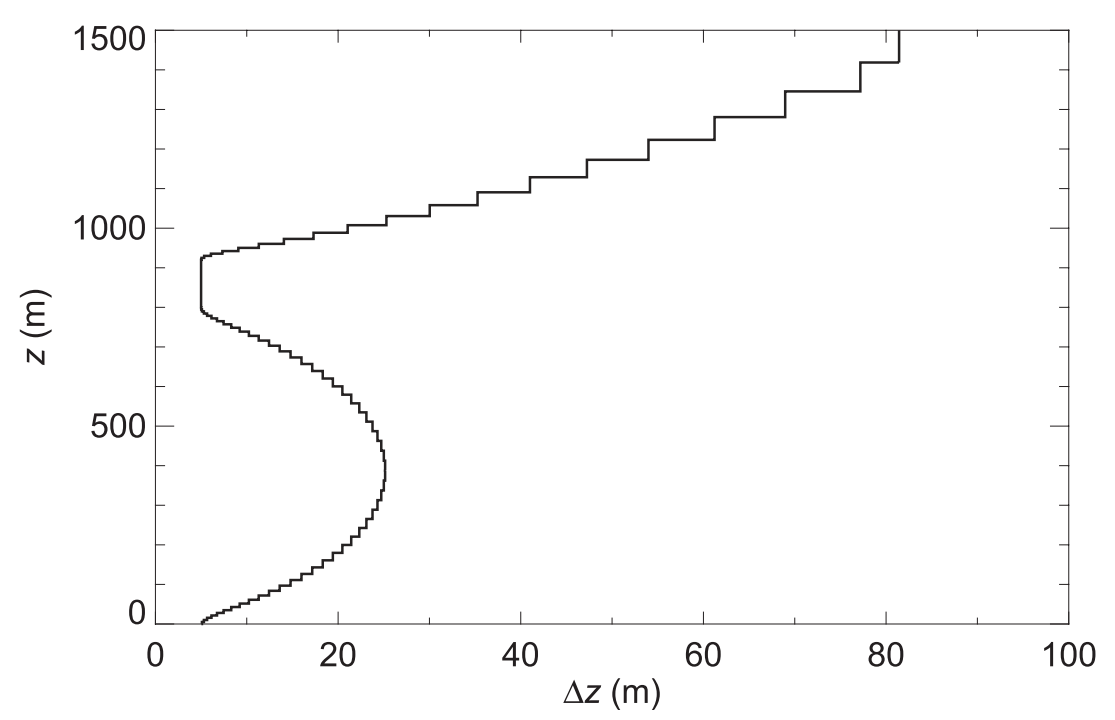

FIG. B1. Vertical grid recomended for all models.

by rain drops, condensation, and sedimentation of rain drops are based on Lin et al. (1983); further details provided by Saito et al. (2001).

\section{f. Reading}

University of Reading solutions provided by S. Weinbrecht, using the MetO model described above, but with a different SGS model, a revised version of the stochastic backscatter model of Weinbrecht and Mason (2008). SGS model is based on Mason and Thomson (1992) but the implementation was improved to ensure an appropriate scale of backscatter, independent of mesh refinement, and is isotropic.

\section{g. RAMS}

Regional Atmospheric Modeling System (RAMS) solutions provided by $\mathrm{H}$. Jiang. Model dynamics are unchanged from Stevens et al. (2005b). A double-moment bin microphysics scheme is used for microphysics, predicting both drop number and mass in each of 33 size bins, with mass doubling between bins, spanning drop radii of $1.56 \mu \mathrm{m}-2.54 \mathrm{~mm}$. Microphysics scheme is described by Tzivion et al. (1987, 1989), and Stevens et al. (1996). Gravitational collision efficiencies follow Hall (1980), and $E_{\text {coal }}=1$. Solute and curvature effects are ignored in the treatment of condensation and evaporation.

TABLE C1. Reported time series, provided at an interval of 5 min or shorter. LWP and precipitation fluxes include all (cloud and rain) condensed water. Cloudy grid cells are defined as those with $N_{d}>20 \mathrm{~cm}^{-3}$ (saturated grid cells for models without microphysics or with parameterized microphysics); cloudy columns are defined as those with of LWP $>20 \mathrm{~g} \mathrm{~m}^{-2}$, a threshold that corresponds to an optical depth of two for cloud droplet effective radius of $15 \mu \mathrm{m}$.

\begin{tabular}{|c|c|c|}
\hline Name & Description & Units \\
\hline time & Time & s \\
\hline $\mathrm{zi}$ & Mean height of $q_{t}=8 \mathrm{~g} \mathrm{~kg}^{-1}$ surface & $\mathrm{m}$ \\
\hline zi_var & Variance of height of $q_{t}=8 \mathrm{~g} \mathrm{~kg}^{-1}$ surface & $\mathrm{m}^{2}$ \\
\hline $\mathrm{zb}$ & Mean height of bottom of lowermost cloudy grid cell & $\mathrm{m}$ \\
\hline zb_var & Variance of height of bottom of lowermost cloudy grid cell & $\mathrm{m}^{2}$ \\
\hline ndrop_cld & Mean $N_{d}$ in cloudy grid cells & $\mathrm{cm}^{-3}$ \\
\hline lwp & Mean LWP & $\mathrm{g} \mathrm{m}^{-2}$ \\
\hline lwp_var & LWP variance & $\mathrm{g}^{2} \mathrm{~m}^{-4}$ \\
\hline cfrac & Fraction of cloudy columns & \\
\hline tke & $0.5 \int_{0}^{1.5} \mathrm{~km} \rho\left(\overline{u^{\prime 2}}+\overline{v^{\prime 2}}+\overline{w^{\prime 2}}\right) d z$ (subgrid-scale plus resolved) & $\mathrm{kg} \mathrm{s}^{-2}$ \\
\hline wstar & $2.5\left[\int_{0}^{1.5 \mathrm{~km}}\left(g / \theta_{v}\right) \overline{w^{\prime} \theta_{v}^{\prime}} d z\right]^{1 / 3}$ (subgrid-scale plus resolved) & $\mathrm{m} \mathrm{s}^{-1}$ \\
\hline w2_max & Maximum value of layer-averaged $\overline{w^{\prime 2}}$ & $\mathrm{~m}^{2} \mathrm{~s}^{-2}$ \\
\hline precip & Mean downward surface precipitation flux & $\mathrm{W} \mathrm{m}^{-2}$ \\
\hline precip_var & Variance of downward surface precipitation flux & $\mathrm{W}^{2} \mathrm{~m}^{-4}$ \\
\hline precip_max & Maximum downward surface precipitation flux & $\mathrm{W} \mathrm{m} \mathrm{m}^{-2}$ \\
\hline
\end{tabular}


TABLE C2. Horizontally averaged profiles. All variables except for the time and heights, which are independent of time, are composed of 12 vertical profiles averaged over 30-min intervals for the duration of the simulations, and one initial profile. Liquid water (e.g., in $q_{l}$ and $\theta_{l}$ ) includes all (cloud and rain) condensed water. Cloudy grid cells are defined as those with $N_{d}>20 \mathrm{~cm}^{-3}$. Rainwater is defined by drops $>25 \mu \mathrm{m}$ radius for bin microphysics models.

\begin{tabular}{|c|c|c|}
\hline Name & Description & Units \\
\hline time & End of averaging interval & $\mathrm{s}$ \\
\hline zt & Altitude of layer midpoints & $\mathrm{m}$ \\
\hline $\mathrm{zW}$ & Altitude of layer boundaries & $\mathrm{m}$ \\
\hline rho & Reference air density & $\mathrm{kg} \mathrm{m}^{-3}$ \\
\hline $\mathrm{u}$ & Zonal wind & $\mathrm{m} \mathrm{s}^{-1}$ \\
\hline $\mathrm{v}$ & Meridional wind & $\mathrm{m} \mathrm{s}^{-1}$ \\
\hline thetal & Liquid water potential temperature & $\mathrm{K}$ \\
\hline qt & Total water (vapor plus liquid) mixing ratio & $\mathrm{g} \mathrm{kg}^{-1}$ \\
\hline $\mathrm{ql}$ & Liquid water mixing ratio & $\mathrm{g} \mathrm{kg}^{-1}$ \\
\hline qr & Rainwater mixing ratio & $\mathrm{g} \mathrm{kg}^{-1}$ \\
\hline cfrac & Fraction of cloudy grid cells & \\
\hline ndrop_cld & Mean $N_{d}$ in cloudy grid cells & $\mathrm{cm}^{-3}$ \\
\hline ss & Mean supersaturation & $\%$ \\
\hline u_var & Resolved $\underline{u^{\prime 2}}$ & $\mathrm{~m}^{2} \mathrm{~s}^{-2}$ \\
\hline v_var & Resolved $\overline{v^{\prime 2}}$ & $\mathrm{~m}^{2} \mathrm{~s}^{-2}$ \\
\hline w_var & Resolved $\overline{w^{\prime 2}}$ & $\mathrm{~m}^{2} \mathrm{~s}^{-2}$ \\
\hline w_skw & Resolved $\overline{w^{\prime 3}}$ & $\mathrm{~m}^{3} \mathrm{~s}^{-3}$ \\
\hline thetal_var & Resolved $\overline{\theta_{l}^{\prime 2}}$ & $\mathrm{~K}^{2}$ \\
\hline qt_var & Resolved $\overline{q_{t}^{\prime 2}}$ & $\mathrm{~g}^{2} \mathrm{~kg}^{-1}$ \\
\hline ql_var & Resolved $\overline{q_{l}^{2}}$ & $\mathrm{~g}^{2} \mathrm{~kg}^{-1}$ \\
\hline rad_flx & Net radiative flux & $\mathrm{W} \mathrm{m} \mathrm{m}^{-2}$ \\
\hline precip & Precipitation flux (positive downward) & $\mathrm{W} \mathrm{m} \mathrm{m}^{-2}$ \\
\hline tot_tw & Total $\theta_{l}$ flux, including subgrid-scale and precipitation & $\mathrm{W} \mathrm{m} \mathrm{m}^{-2}$ \\
\hline sgs_tw & Subgrid-scale $\theta_{l}$ flux & $\mathrm{W} \mathrm{m} \mathrm{m}^{-2}$ \\
\hline tot_qw & Total $q_{t}$ flux, including subgrid-scale and precipitation & $\mathrm{W} \mathrm{m} \mathrm{m}^{-2}$ \\
\hline sgs_qw & Subgrid-scale $q_{t}$ flux & $\mathrm{W} \mathrm{m} \mathrm{m}^{-2}$ \\
\hline tot_uw & Total (subgrid-scale plus resolved) zonal momentum flux & $\mathrm{kg} \mathrm{m}^{-1} \mathrm{~s}^{-2}$ \\
\hline sgs_uw & Subgrid-scale zonal momentum flux & $\mathrm{kg} \mathrm{m}^{-1} \mathrm{~s}^{-2}$ \\
\hline tot_vw & Total (subgrid-scale plus resolved) meridional momentum flux & $\mathrm{kg} \mathrm{m}^{-1} \mathrm{~s}^{-2}$ \\
\hline sgs_vw & Subgrid-scale meridional momentum flux & $\mathrm{kg} \mathrm{m}^{-1} \mathrm{~s}^{-2}$ \\
\hline sgs_pr & Subgrid-scale Prandtl number & \\
\hline sgs_tke & Subgrid-scale TKE & $\mathrm{m}^{2} \mathrm{~s}^{-2}$ \\
\hline tot_boy & Total (subgrid-scale plus resolved) buoyancy TKE production & $\mathrm{m}^{2} \mathrm{~s}^{-3}$ \\
\hline sgs_boy & Subgrid-scale buoyancy TKE production & $\mathrm{m}^{2} \mathrm{~s}^{-3}$ \\
\hline tot_shr & Total (subgrid-scale plus resolved) shear TKE production & $\mathrm{m}^{2} \mathrm{~s}^{-3}$ \\
\hline transport & Resolved TKE transport (turbulent plus pressure) & $\mathrm{m}^{2} \mathrm{~s}^{-3}$ \\
\hline dissipation & TKE dissipation (explicit plus numerical) & $\mathrm{m}^{2} \mathrm{~s}^{-3}$ \\
\hline
\end{tabular}

\section{h. $S A M$}

System for Atmospheric Modeling (SAM) solutions provided by M. Khairoutdinov. Model dynamics are unchanged from Stevens et al. (2005b), and microphysics parameterization described by KK00.

\section{i. UCLA}

University of California, Los Angeles (UCLA) solutions provided by V. Savic-Jovcic and B. Stevens. Model dynamics are unchanged from UCLA-0 in Stevens et al. (2005b), although here SGS diffusivity is damped with distance from the surface, with a 100-m length scale, to more smoothly match boundary conditions. Away from the surface SGS scalar fluxes were carried by nu- merical dissipation of advection scheme. The microphysics scheme carries $q_{r}$ and $N_{r}$ as prognostic variables; $q_{c}$ is diagnosed as the positive definite residual between equilibrium $q_{l}$ and prognostic $q_{r}$. Microphysics follows two prescriptions, one KK00 and the other Seifert and Beheng (2001, 2006); denoted respectively as UCLA and UCLA_SB. In both implementations, cloud droplets correspond to radii less than $25 \mu \mathrm{m}$.

\section{j. Utah}

University of Utah solutions provided by M. Zulauf and S. Krueger. The model (Zulauf 2001) solves compressible equations using the quasi-compressibility approximation of Droegemeier and Wilhelmson (1987). 
Scalar advection uses third-order upwinding (Stevens and Bretherton 1996), with monotonicity maintained using flux-corrected transport (Zalesak 1979). Momentum advection uses the third-order upwinding scheme of Wicker and Skamarock (1998), which also provides the basis for the time-split second-order Runge-Kutta time stepping. SGS mixing is parameterized with a prognostic TKE scheme (Deardorff 1980b). Microphysics uses a saturation adjustment step, along with a singlemoment, mixed-phase bulk scheme (Lin et al. 1983; Lord et al. 1984; Krueger et al. 1995b). Autoconversion follows modified Liu and Daum (2004) formula in Wood (2005b), using the threshold function from Liu et al. (2005).

\section{k. $W V U$}

West Virginia University (WVU) solutions provided by D. Lewellen. Model dynamics are unchanged from WVU-0 in Stevens et al. (2005b). A bulk Kessler-type microphysics scheme is used, carrying $q_{r}$ and $N_{r}$ as prognostic variables. Parameterizations for autoconversion, accretion, evaporation, and fall speeds follow KK00.

\section{APPENDIX C}

\section{Description of Model Output Files}

The netCDF output files archived at the GCSS DIME Web site consists of all the requested time series and profiles, as described in Tables $\mathrm{C} 1$ and $\mathrm{C} 2$.

\section{REFERENCES}

Ackerman, A. S., O. B. Toon, J. P. Taylor, D. W. Johnson, P. V. Hobbs, and R. J. Ferek, 2000: Effects of aerosols on cloud albedo: Evaluation of Twomey's parameterization of cloud susceptibility using measurements of ship tracks. J. Atmos. Sci., 57, 2684-2695.

— M. P. Kirkpatrick, D. E. Stevens, and O. B. Toon, 2004: The impact of humidity above stratiform clouds on indirect aerosol climate forcing. Nature, 432, 1014-1017.

Albrecht, B., 1989: Aerosols, cloud microphysics, and fractional cloudiness. Science, 245, 1227-1230.

Beard, K. V., 1976: Terminal velocity and shape of cloud and precipitation drops aloft. J. Atmos. Sci., 33, 851-864.

— for accretion. J. Geophys. Res., 89, 7165-7169.

Bony, S., and J. Dufresne, 2005: Marine boundary layer clouds at the heart of tropical cloud feedback uncertainties in climate models. Geophys. Res. Lett., 32, L20806, doi:10.1029/ 2005 GL023851.

Bougeault, P., 1985: The diurnal cycle of the marine stratocumulus layer: A higher-order model study. J. Atmos. Sci., 42, 2826-2843.

Boville, B., P. Rasch, J. Hack, and J. McCaa, 2006: Representation of clouds and precipitation processes in the Community Atmosphere Model version 3 (CAM3). J. Climate, 19, 2184-2198.
Bretherton, C., and M. Wyant, 1997: Moisture transport, lowertropospheric stability, and decoupling of cloud-topped boundary layers. J. Atmos. Sci., 54, 148-167.

_- P. Blossey, and J. Uchida, 2007: Cloud droplet sedimentation, entrainment efficiency, and subtropical stratocumulus albedo. Geophys. Res. Lett., 34, L03813, doi:10.1029/2006GL027648.

Brost, R., J. Wyngaard, and D. Lenschow, 1982: Marine stratocumulus layers. Part II: Turbulence budgets. J. Atmos. Sci., 39, 818-836.

Coakley, J. A., Jr., and C. D. Walsh, 2002: Limits to the aerosol indirect radiative effect derived from observations of ship tracks. J. Atmos. Sci., 59, 668-680.

Comstock, K. K., R. Wood, S. E. Yuter, and C. S. Bretherton, 2004: Reflectivity and rain rate in and below drizzling stratocumulus. Quart. J. Roy. Meteor. Soc., 130, 2891-2918.

Deardorff, J. W., 1980a: Cloud top entrainment instability. J. Atmos. Sci., 37, 131-147.

— 1980b: Stratocumulus-capped mixed layers derived from a three-dimensional model. Bound.-Layer Meteor., 18, 495-527.

Droegemeier, K. K., and R. B. Wilhelmson, 1987: Numerical simulation of thunderstorm outflow dynamics. Part I: Outflow sensitivity experiments and turbulence dynamics. J. Atmos. Sci., 44, 1180-1210.

Faloona, I., and Coauthors, 2005: Observations of entrainment in eastern Pacific marine stratocumulus using three conserved scalars. J. Atmos. Sci., 62, 3268-3285.

Golaz, J.-C., S. Wang, J. D. Doyle, and J. M. Schmidt, 2005: COAMPS $^{\circledR}$-LES: Model evaluation and analysis of second and third moment vertical velocity budgets. Bound.-Layer Meteor., 116, 487-517.

Hall, W. D., 1980: A detailed microphysical model within a twodimensional dynamic framework: Model description and preliminary results. J. Atmos. Sci., 37, 2486-2507.

Jiang, H., G. Feingold, and W. R. Cotton, 2002: Simulations of aerosol-cloud-dynamical feedbacks resulting from entrainment of aerosol into the marine boundary layer during the Atlantic Stratocumulus Transition Experiment. J. Geophys. Res., 107, 4813, doi:10.1029/2001JD001502.

Khairoutdinov, M. F., and Y. L. Kogan, 2000: A new cloud physics parameterization in a large-eddy simulation model of marine stratocumulus. Mon. Wea. Rev., 128, 229-243.

Klein, S., and D. Hartmann, 1993: The seasonal cycle of low stratiform clouds. J. Climate, 6, 1587-1606.

Klemp, J. B., and R. B. Wilhelmson, 1978: The simulation of threedimensional convective storm dynamics. J. Atmos. Sci., 35, 1070-1096.

Krueger, S., G. McLean, and Q. Fu, 1995a: Numerical simulation of the stratus-to-cumulus transition in the subtropical marine boundary layer. Part I: Boundary-layer structure. J. Atmos. Sci., 52, 2839-2850.

— Q. Fu, K. N. Liou, and H.-N. S. Chin, 1995b: Improvements of an ice-phase microphysics parameterization for use in numerical simulations of tropical convection. J. Appl. Meteor., 34, 281-287.

Larson, V. E., K. E. Kotenberg, and N. B. Wood, 2007: An analytic longwave radiation formula for liquid layer clouds. Mon. Wea. Rev., 135, 689-699.

Lewellen, D., and W. Lewellen, 2002: Entrainment and decoupling relations for cloudy boundary layers. J. Atmos. Sci., 59, 29662986.

Lin, Y.-L., R. D. Farley, and H. D. Orville, 1983: Bulk parameterization of the snow field in a cloud model. J. Climate Appl. Meteor., 22, 1065-1092. 
Liu, Y., and P. H. Daum, 2004: Parameterization of the autoconversion process. Part I: Analytical formulation of the Kessler-type parameterizations. J. Atmos. Sci., 61, 1539-1548.

- - - , and R. L. McGraw, 2005: Size truncation effect, threshold behavior, and a new type of autoconversion parameterization. Geophys. Res. Lett., 32, L11811, doi:10.1029/ 2005 GL022636.

Lord, S. J., H. E. Willoughby, and J. M. Piotrowicz, 1984: Role of a parameterized ice-phase microphysics in an axisymmetric, non-hydrostatic tropical cyclone model. J. Atmos. Sci., 41, 2836-2848.

Lüpkes, C., 1991: Untersuchungen zur Parametrisierung von Koagulationsprozessen nieder-schlagsbildender Tropfen. Verlag Dr. Kovač, Hamburg, Germany, 156 pp.

Martin, G. M., D. W. Johnson, and A. J. Spice, 1994: The measurement and parameterization of effective radius of droplets in warm stratocumulus clouds. J. Atmos. Sci., 51, 1823-1842.

Mason, P. J., and D. J. Thomson, 1992: Stochastic backscatter in largeeddy simulations of boundary layers. J. Fluid Mech., 242, 51-78.

Mitchell, D., P. Rasch, D. Ivanova, G. McFarquhar, and T. Nousiainen, 2008: Impact of small ice crystal assumptions on ice sedimentation rates in cirrus clouds and GCM simulations. Geophys. Res. Lett., 35, L09806, doi:10.1029/2008GL033552.

Moeng, C., 1986: Large-eddy simulation of a stratus-topped boundary layer. Part I: Structure and budgets. J. Atmos. Sci., 43, 2886-2900.

_ , and R. Rotunno, 1990: Vertical-velocity skewness in the buoyancy-driven boundary layer. J. Atmos. Sci., 47, 1149-1162.

Nicholls, S., 1984: The dynamics of stratocumulus: Aircraft observations and comparisons with a mixed layer model. Quart. J. Roy. Meteor. Soc., 110, 783-820.

_ , and J. Leighton, 1986: An observational study of the structure of stratiform cloud sheets: Part I. Structure. Quart. J. Roy. Meteor. Soc., 112, 431-460.

Paluch, I., and D. Lenschow, 1991: Stratiform cloud formation in the marine boundary layer. J. Atmos. Sci., 48, 2141-2158.

Pawlowska, H., and J.-L. Brenguier, 2003: An observational study of drizzle formation in stratocumulus clouds for general circulation model (GCM) parameterizations. J. Geophys. Res., 108, 8630, doi:10.1029/2002JD002679.

Petters, M. D., J. R. Snider, B. Stevens, G. Vali, I. Faloona, and L. Russell, 2006: Accumulation mode aerosol, pockets of open cells, and particle nucleation in the remote subtropical Pacific marine boundary layer. J. Geophys. Res., 111, D02206, doi:10.1029/2004JD005694.

Pincus, R., and M. B. Baker, 1994: Effect of precipitation on the albedo susceptibility of clouds in the marine boundary layer. Nature, 372, 250-252.

Platnick, S., and Coauthors, 2000: The role of background cloud microphysics in the radiative formation of ship tracks. $J$. Atmos. Sci., 57, 2607-2624.

Randall, D. A., 1980: Conditional instability of the first kind upside-down. J. Atmos. Sci., 37, 125-130.

_ 1984: Stratocumulus cloud deepening through entrainment. Tellus, 36A, 446-457.

GEWEX Cloud Systems Study. Bull. Amer. Meteor. Soc., 84, 455-469.

Richard, E., and N. Chaumerliac, 1989: Effects of different rain parameterizations on the simulation of mesoscale orographic precipitation. J. Appl. Meteor., 28, 1197-1212.

Rogers, R. R., 1979: A Short Course in Cloud Physics. 2nd ed. Pergamon Press, 227 pp.
Saito, K., T. Kato, H. Eito, and C. Muroi, 2001: Documentation of the Meteorological Research Institute/Numerical Prediction Division unified nonhydrostatic model. Tech. Rep. 16, Meteorological Research Institute-Japanese Meteorological Agency, $133 \mathrm{pp}$.

Seifert, A., and K. D. Beheng, 2001: A double-moment parameterization for simulating autoconversion, accretion and self collection. Atmos. Res., 59-60, 265-281.

—, and 2006: A two-moment cloud microphysics parameterization for mixed-phase clouds. Part 1: Model description. Meteor. Atmos. Phys., 92, 45-66.

Snider, J. R., M. D. Petters, P. Wechsler, and P. Liu, 2006: Supersaturation in the Wyoming $\mathrm{CCN}$ instrument. J. Atmos. Oceanic Technol., 23, 1323-1339.

Stevens, B., 2000: Cloud transitions and decoupling in shear-free stratocumulus-topped boundary layers. Geophys. Res. Lett., 27, 2557-2560

—, G. Feingold, W. R. Cotton, and R. L. Walkso, 1996: Elements of the microphysical structure of numerically simulated nonprecipitating stratocumulus. J. Atmos. Sci., 53, 980-1006.

, W. R. Cotton, G. Feingold, and C.-H. Moeng, 1998: Largeeddy simulations of strongly precipitating, shallow, stratocumulus-topped boundary layers. J. Atmos. Sci., 55, 36163638

, and Coauthors, 2003a: Dynamics and chemistry of marine stratocumulus-DYCOMS-II. Bull. Amer. Meteor. Soc., 84, 579-593.

, and Coauthors, 2003b: On entrainment rates in nocturnal marine stratocumulus. Quart. J. Roy. Meteor. Soc., 129, 34693493.

-, G. Vali, K. Comstock, M. C. vanZanten, P. H. Austin, C. S. Bretherton, and D. Lenschow, 2005a: Pockets of open cells (POCs) and drizzle in marine stratocumulus. Bull. Amer. Meteor. Soc., 86, 51-57.

, and Coauthors, 2005b: Evaluation of large-eddy simulations via observations of nocturnal marine stratocumulus. Mon. Wea. Rev., 133, 1443-1462.

Stevens, D. E., and C. S. Bretherton, 1996: A new forward-in-time advection scheme and adaptive multilevel flow solver for nearly incompressible atmospheric flow. J. Comput. Phys., 129, 284-295.

Turton, J. D., and S. Nicholls, 1987: Diurnal variation of stratocumulus. Quart. J. Roy. Meteor. Soc., 113, 969-1009.

Twomey, S., 1974: Pollution and the planetary albedo. Atmos. Environ., 8, 1251-1256.

Tzivion, S., G. Feingold, and Z. Levin, 1987: An efficient numerical solution to the stochastic collection equation. J. Atmos. Sci., 44, 3139-3149.

,$- \ldots$, and ——, 1989: The evolution of raindrop spectra. Part II: Collisional collection/breakup and evaporation in a rain shaft. J. Atmos. Sci., 46, 3312-3327.

vanZanten, M. C., and B. Stevens, 2005: Observations of the structure of heavily precipitating marine stratocumulus. J. Atmos. Sci., 62, 4327-4342.

,,-- G. Vali, and D. Lenschow, 2005: Observations of drizzle in nocturnal marine stratocumulus. J. Atmos. Sci., 62, 88-106.

Weinbrecht, S., and P. Mason, 2008: Stochastic backscatter for cloud-resolving models. Part I: Implementation and testing in a dry convective boundary layer. J. Atmos. Sci., $\mathbf{6 5}, 123-139$

Wicker, L. J., and W. C. Skamarock, 1998: A time-splitting scheme for the elastic equations incorporating second-order RungeKutta time differencing. Mon. Wea. Rev., 126, 1992-1999. 
Wood, R., 2005a: Drizzle in stratiform boundary layer clouds. Part I: Vertical and horizontal structure. J. Atmos. Sci., 62, 3011-3033. , 2005b: Drizzle in stratiform boundary layer clouds. Part II: Microphysical aspects. J. Atmos. Sci., 62, 3034-3050.

- 2007: Cancellation of aerosol indirect effects in marine stratocumulus through cloud thinning. J. Atmos. Sci., 64, 2657-2669.

Wyant, M., and Coauthors, 2007: A single-column model intercomparison of a heavily drizzling stratocumulus-topped boundary layer. J. Geophys. Res., 112, D24204, doi:10.1029/ 2007JD008536.

Zalesak, S. T., 1979: Fully multidimensional flux-corrected transport. J. Comput. Phys., 31, 335-362.

Zulauf, M. A., 2001: Modeling the effects of boundary layer circulations generated by cumulus convection and leads on largescale surface fluxes. Ph.D. thesis, University of Utah, $177 \mathrm{pp}$. [Available online at http://www.met.utah.edu/skrueger/ homepages/mazulauf/files/zulauf_thesis_final.pdf.] 